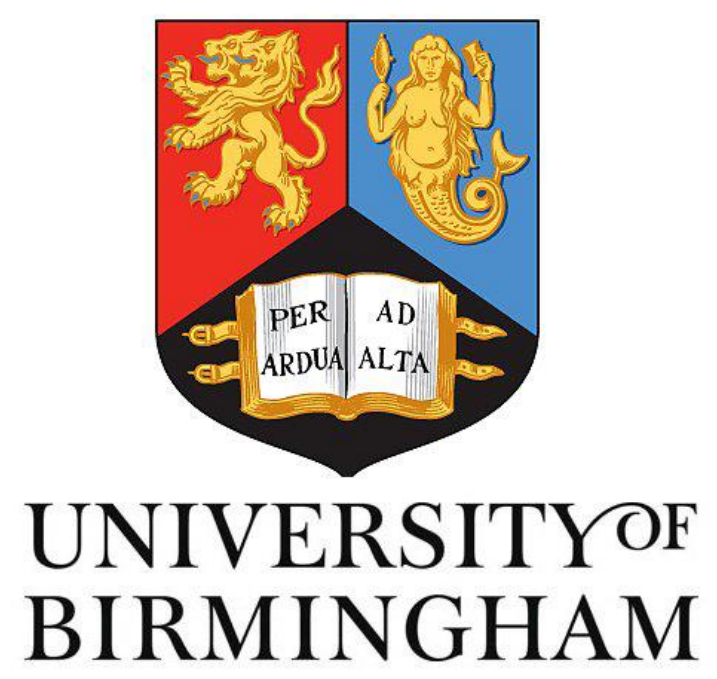

School of Government and Society

International Development Department

\title{
Does Decentralization Improve Provision of Health Services? Evidence from Kisumu and Makueni Counties in Kenya
}

A Dissertation Submitted to the University of Birmingham in Partial Fulfilment of the Requirements for the Award of the Degree of Master of Science in International Development

(International Political Economy and Development)

\section{Racheal Omukhulu Makokha}

(1710748)

Supervised by

Dr Philip Amis 


\section{Acknowledgements}

My deepest gratitude goes to the Commonwealth Scholarship Commission for awarding me a full scholarship to undertake my studies at the University of Birmingham. I am thankful to my Supervisor, Dr Philip Amis, for his ever prompt feedback, guidance and being the most supportive and understanding academic advisor.

Thanks to Ludivicus for being my support system when I thought I was going to lose it-for reminding me each day of my potential.

Finally, to my friends from IDD and Elim Church Selly Oak Connect group, thank you for making my stay in Birmingham unforgettable. 


\begin{abstract}
The last five decades have seen uncountable debates on the impact of decentralization on provision of public services. While it has evidently improved public service delivery in some countries, it has worsened it in others. Kenya implemented devolution in 2013 in the hope of bringing public services nearer to the people. Health was one of the services identified. Yet, the local media has reported negative impact of devolution on provision of health services since 2013. This study sought to look at the actual effect of devolution on access to health care services by analysing secondary quantitative data from the government published data, official statistics, international development agencies' surveys and reports. Two county governments; Kisumu and Makueni were chosen to represent the urban and rural populations respectively. Contrary to the wider literature on health decentralization, this study found out that devolution did not worsen access to health care services in Kenya. The study attributed this to the nature of devolution adopted in the country where the county governments have considerable authority, decision-making power and responsibility over their counties.
\end{abstract}




\section{Table of Contents}

Acknowledgements $\quad 2$

$\begin{array}{ll}\text { Abstract } & 3\end{array}$

List of Figures and Tables $\quad 5$

$\begin{array}{lr}\text { Acronyms } & 6\end{array}$

$\begin{array}{lr}\text { 1.Introduction } & 7\end{array}$

$\begin{array}{ll}1.1 \text { Background } & 7\end{array}$

1.2 Key Research Concepts $\quad 8$

1.3 Research Purpose and Significance $\quad 8$

1.4 Research Objectives $\quad 8$

1.5 Research Questions $\quad 9$

1.6 Limitations of Research 9

1.7 Structure of the Dissertation 9

2. Literature Review 10

$\begin{array}{ll}2.1 \text { Introduction } & 10\end{array}$

$\begin{array}{ll}2.2 \text { Decentralization } & 10\end{array}$

2.3 Access to Health Care $\quad 12$

2.3.1 Availability 14

2.3.2 Accessibility 14

2.3.3 Affordability 14

$\begin{array}{ll}2.4 \text { Conceptual Framework } & 14\end{array}$

2.5 Health Decentralization $\quad 15$

$\begin{array}{ll}2.6 \text { Devolution in Kenya } & 17\end{array}$

2.7 Devolution of Health Sector in Kenya $\quad 21$

$\begin{array}{ll}2.8 \text { Summary } & 24\end{array}$

3. Methodology 25

3.1 Research Strategy \& Design $\quad 25$

3.2 Research Purpose $\quad 25$

3.3 Sources of Data $\quad 26$

3.4 Choice of Data Analysis Methods $\quad 27$

3.5 Limitations of Research $\quad 27$

$\begin{array}{lr}\text { 4. Kenya's Background } & 29\end{array}$

$\begin{array}{ll}4.1 \text { Kisumu County } & 31\end{array}$

4.2 Makueni County $\quad 32$

5. Impact of Devolution on Access to Health Care in Kenya

$\begin{array}{ll}5.1 \text { Availability } & 35\end{array}$

$\begin{array}{ll}5.2 \text { Accessibility } & 38\end{array}$

$\begin{array}{ll}5.3 \text { Affordability } & 40\end{array}$

6. Discussion and Conclusion $\quad 43$

6.1 Discussion $\quad 43$

6.2 Comparing findings to the wider literature 48

6.2.1 Availability $\quad 48$

6.2.3 Accessibility $\quad 49$

6.2.4 Affordability $\quad 50$

$\begin{array}{ll}6.3 \text { Conclusion } & 50\end{array}$

$\begin{array}{lr}\text { References } & 53\end{array}$ 


\section{List of Figures and Tables}

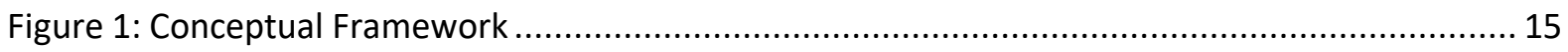

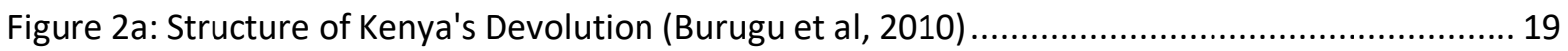

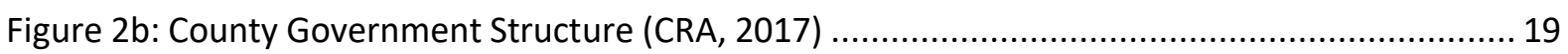

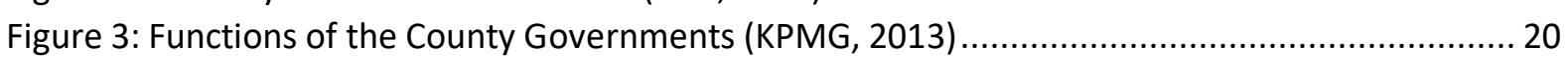

Figure 4: Separation of Responsibilities for Health (Kenya Health Policy 2014-2030)....................... 22

Figure 5: Kenya's Devolved Health System Hierarchy (Nyikuri et al, 2015) ..................................... 23

Figure 6: Distribution of Health Inputs among Kenya's 47 Counties (Kenya Health Expenditure

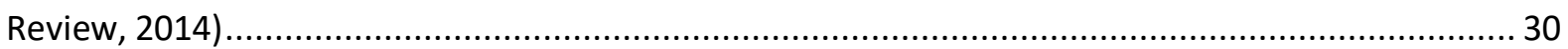

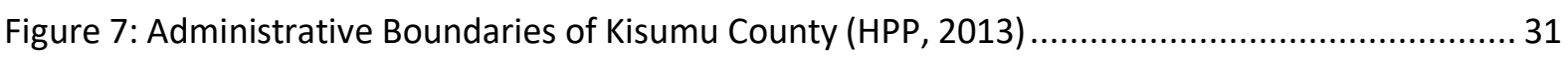

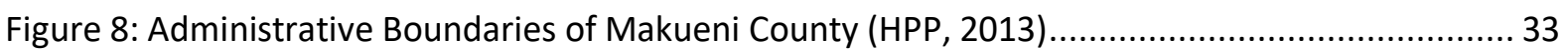

Table 1: Kisumu, Makueni Counties and Kenya's average statistics based on multiple sources.... Error!

\section{Bookmark not defined.}

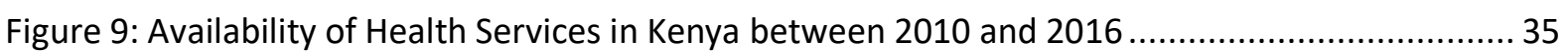

Figure 10: Availability of Health Services in Kisumu County between 2013 and 2016 ...................... 36

Figure 11: Availability of health services in Makueni County between 2013 and 2016 .................... 37

Figure 12: Accessibility of health services in Kenya between 2010 and 2016 ................................. 38

Figure 13: Accessibility of health services in Kisumu County between 2010 and 2016 ..................... 39

Figure 14: Accessibility of health Services in Makueni County between 2010 and 2016.................... 39

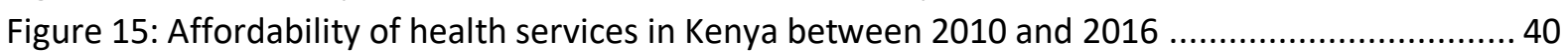

Figure 16: Affordability of health services in Kisumu County between 2010 and 2016 .................... 41

Figure 17: Affordability of health services in Makueni County between 2010 and 2016 .................. 41

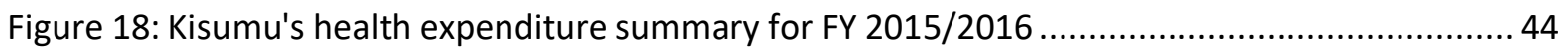

Figure 19: Makueni's health expenditure summary for the FY 2015/2016 ...................................... 46 


\section{Acronyms}

CRA Commission on Revenue Allocation

DHMTs District Health Management Teams

DFRD District Focus for Rural Development

FY

Financial Year

HIV/AIDS Human Immunodeficiency Virus/Acquired Immune Deficiency Syndrome

HPP Health Policy Project

KANU Kenya African National Union

KDHS Kenya Demographic Health Survey

KEMRI Kenya Medical Research Institute

KEMSA Kenya Medical Supplies Agency

KMTC Kenya Medical Training College

$\mathrm{MoH} \quad$ Ministry of Health

NARC National Alliance of Rainbow Coalition

NHIF National Hospital Insurance Fund

OOP Out of Pocket Expenditure

PHMTs Provincial Health Management Teams

SARAM Service Availability and Readiness Assessment Mapping

SPA Service Provision Assessment

WHO World Health Organization 


\section{Introduction}

\subsection{Background}

According to Robinson (2003), while decentralization has improved public service management in other places, it has not led to any reforms in Africa. He blames this on the lack of political commitment, limited allocation of resources, lack of local units' capacity and lack of legal backing of decentralization changes. However, as World Bank (2014) puts it, Kenya's decentralization is a unique case in Africa. It was implemented in 2013 with the full support of the political class, central ministries' bureaucrats, the public and a legal document. The 47 county governments created by devolution are allocated at least $15 \%$ of all the national revenue collected every financial year (Constitution of Kenya, 2010). Kenya thus presents a unique case to study the impact of devolution. One of the most noticeable functions of the county governments is health.

Globally, health sectors face complex challenges (KPMG, 2013). Governments have taken structural or policy changes to improve the performance of their health systems. One of these structural changes is decentralization. It has been argued that decentralization improves efficiency, equity, access, delivery, accountability and responsiveness of the health system (World Bank, 2004; WHO, 2008). However, studies carried out in Africa presents a negative effect of decentralization on health (Bossert \& Beauvais, 2002; Andrews \& Schroeder, 2003; Mehortra, 2006). Currently, Kenya seems to be following this trend. Since 2013, the devolved health sector has experienced considerable challenges including an unparalleled number of strikes by healthcare workers (Masika, 2016).

Although this is the case, it is important to note that the health sector in Kenya had previously been decentralised albeit with less significant responsibilities to the deconcentrated units (Mwabu, 2009). The deconcentration phase was a result of the observed disparities in access to healthcare services in the country. This was blamed on the highly centralised decision-making process in the health sector $(\mathrm{MoH}, 2006)$. Following this, there was the implementation of the 1994 Kenya Health Policy Framework aimed at providing cheap, decent, reachable and quality health care for everyone. The Kenyan constitution (2010) has since replaced this framework and significantly affected the 
structure of the health sector. The constitution stipulates that the Ministry of Health limits its functions to regulation, policy making and ownership of tertiary level facilities while county governments take over the function of provision of health services and managing health care funds (Barasa et al., 2017). This has been argued to result in the decline of quality of health services (Gathura, 2015; Nyambane, 2014), frequent drugs stock out (Ndavi et al., 2009) low morale within the health workforce (Momanyi, 2016; Oyugi, 2015; Nyongesa et al., 2014; Ojakaa et al, 2014) and lack of technical support (Agoro et al, 2015) in the health sector. The negative impact is generally seen in studies that have measured social perspectives. This excludes one qualitative study (Kilonzo et al., 2017), whose findings showed a positive view of the impact of devolution on access to maternal healthcare by the users.

None of these has investigated the impact of devolution on provision of health services and specifically access to health care services using quantitative methods. This research fills this gap by using secondary quantitative methods to establish if the results will reflect the wider literature.

\subsection{Key Research Concepts}

The key concepts of this research topic are devolution, availability, accessibility and affordability of health care services. These will be discussed in detail in the literature review section.

\subsection{Research Purpose and Significance}

Despite the many studies on impact of decentralization on health, very few have studied African contexts and particularly Kenya which recently implemented a unique form of decentralization. Decentralization has been argued to improve health provision in some countries and worsen it in others. The main aim of this study was to find out if devolution has improved the provision of health services in Kenya. The focus of the research was on the impact of devolution on access to healthcare services in Kenya. This contributes to the wider literature on health decentralization which to date remains largely debatable.

\subsection{Research Objectives}

The specific objectives of the research were: 
i. To determine if devolution increased availability of; health workforce, health facilities, health infrastructure and health products,

ii. To find out if devolution increased accessibility of health facilities,

iii. To investigate if devolution reduced the costs of healthcare services,

iv. To examine if there are any rival explanations for changes in the health sector inputs post devolution.

From these objectives, the following research questions emerged.

\subsection{Research Questions}

i. Has devolution increased availability of; health workforce, health facilities, health infrastructure and health products?

ii. Has devolution increased accessibility of health facilities?

iii. Has devolution reduced the costs of healthcare services

iv. Are there any rival explanations for the changes in the health sector inputs post devolution?

\subsection{Limitations of the Research}

Devolution in Kenya is a very recent phenomenon with only four years of implementation. One of the limitations of this research therefore may be that it is too early to evaluate its impact. Instead of comparing pre- and post devolution, this research will narrow its temporal scope to between 2013 and 2016 to examine the trends of the health inputs.

\subsection{Structure of the dissertation}

Following this section is chapter two which reviews the literature to explain the concepts used. The concepts are contextualized while also identifying gaps in the literature. Chapter three discusses the research methodology justifying the choice of design, strategy, methods of data collection and data analysis. Chapter four then gives the case study background. Right after this, chapter five presents the findings. The last chapter discusses the findings and gives an evidence backed conclusion to answer the general research question. 


\section{Literature Review}

\subsection{Introduction}

This section presents a review of the literature on the research area using a multidisciplinary approach. It seeks to understand concepts and issues in the research area. The immediate section discusses what decentralization is and the arguments for and against it. The discussion shifts to explaining the concept of access to health care and identifies the researcher's conceptual framework. The debate on health decentralization follows in an attempt to fit the researcher's conceptual framework. The last section concludes by examining devolution in Kenya and gives the context of the country's devolved health system.

\subsection{Decentralization}

Decentralization is a multidisciplinary concept. (Smith 1985; Burns et al. 1994; Exworthy 1994; Pollitt et al. 1998). This only means that the concept remains contested to date with no clear definition. Peckham et al (2008) explains that there have been attempts to define it along spatial and organization lines with regards to administrative and political decentralization. Despite this contest, most scholars agree that, decentralisation is a process of transferring authority, management and decision-making responsibilities from the central government to lower levels of local government (Rondinelli, 1981; Rondinelli et al., 1989; Mills et al., 1990; Collins \& Green, 1994; Mills, 1994; Litvack et al. 1998).

Rondinelli (1981) identifies two forms of decentralization. The first one is the functional and area decentralization. Functional means transfer of power to perform specific tasks to specialized organization that operate nationally whereas area means transfer of responsibility to organizations within well-defined political boundaries such as districts to perform functions strictly within their boundaries respectively(ibid). The second distinction is the most commonly referred in the literature: the degree of decentralization. While Rondinelli (1981) describes this as de-concentration, delegation and devolution, Robinson (2007) describes it as political, fiscal and administrative. To avoid deviating to the types of decentralization debate, this research will use Rondinelli's second distinction of decentralization. 
According to Rondinelli (1981), de-concentration is transferring workload to staff in field offices outside the capital; delegation is transferring decision-making, management and authority over some functions to organizations under indirect control of the central government such as authorities, parastatals and corporations whereas devolution is the creation of autonomous and independent units of government that have clear and legally recognized boundaries within which they exercise their power and perform their functions. Rondinelli (1981) argues that devolution is the most extreme form of decentralization and in fact can be considered as quite separate from decentralization due to its autonomy in the government structure. However, some countries employ two degrees of decentralization (Mills et al, 1990). Therefore, it is imperative to focus on the functions of decentralization rather than the form it takes (Robinson, 2007).

Decentralization policies in most developing countries became fashionable in the 1970s (Conyers, 1983; Mills et al, 1990). This was motivated by different reasons. In some countries, there was widespread dissatisfaction with the over-centralized development planning. In others, it was viewed as a way of mobilizing support for national development plans by making them known at local level while others viewed it as a way of ensuring equity in the allocation of government resources (Rondinelli \& Nellis, 1986). Ultimately, though, it can be argued that decentralization was pushed by development partners (Regmi et al, 2010) who introduced structural adjustment policies meant to steer growth, improve living conditions of the poor, promote efficient delivery of services and seek more equitable distribution of the benefits of economic growth (UNDP, 1979; Mills et al, 1990; World Bank, 2004; Peckham et al, 2005).

Homedes and Ugalde (2005) contend that these structural adjustment policies do not better the efficiency, equity or quality of health care systems. They explain that this is because the reforms do not take into account the context of the countries. Mutizwa-Mangiza (2000) affirms this by stating that many African countries adopted this policy without evaluating their experiences. Litvack et al (1998) points out that the problem with this push was the failure by development partners to foresee the financial, capacity and political challenges of decentralizing in developing countries. But Rondinelli (1981) argues that these challenges stem from problems of lack of political commitment from the central government who are 
unwilling to transfer those crucial functions that provide them with their base for political influence and financial resources. In addition, as most countries grapple with staff shortage at the central ministry level, decentralizing only exacerbates the shortage leading to capacity issues. Finally, decentralizing the functions of raising revenue increases inequality as some regions have small revenue bases that can't finance their functions (Rondinelli, 1983; Litvack et al, 1998). It is indeed interesting to note that some European countries for example Italy, Spain and Norway are recentralizing their health systems because of these challenges (Mosca, 2005; Cinar, 2013).

Regardless of this, decentralization is still in fashion. World Bank (2004) argues that this is because it reduces the distance between politicians, policy makers and the population whilst ensuring services are delivered more effectively and efficiently. WHO (2008) adds that it makes services such as health more equitable, inclusive and fair. Having looked at the decentralization debate, this subsequent section will shift to examining the concept of access.

\subsection{Access to Health Care}

Access to primary health care was declared a human right during the Alma Ata Conference in 1978 (To, 2003). Access is a complex multidimensional concept (Gulliford et al., 2002; Social Protection Committee, 2013). The McGraw-Hill Concise Dictionary of Modern Medicine (2002) defines it as the capacity of someone to get health care services as a result of availability of health workforce and medicine stock, and their capacity to pay for those services.

However, this is a limited definition as access involves more than availability and affordability. Gulliford et al. (2002) contend that the available services should meet the people's needs for the goal of access to be achieved. Penchansky and Thomas (1981) agree as they define access as the extent of 'fit' between the patients and the organization. The US Institute of Medicine (1993) on the other hand, defines access as the appropriate utilisation of health services to attain the best result.

Aday and Anderson (1975) offer a different way of defining access as overcoming the obstacles to the required services while Parker (1974) defines it as the capability to reach 
and afford health services. Freeborn and Greenlik (1973) add that access includes getting the services whenever or wherever one needs it.

Mechanic (1972) proposes a different view altogether. He defines access as the readiness by the patients to look for treatment. He argues that this depends on the patients' health beliefs, awareness, and their community's interpretation of diseases.

With all these competing definitions, Gulzar (1999) argues that WHO presents the most exhaustive definition in its attempt to explain primary health care. According to WHO (1978), access refers to

"...the continuing and organized supply of care that is geographically, financially, culturally, and functionally within easy reach of the whole community. The care has to be appropriate and adequate in content and in amount to satisfy the needs of people and it has to be provided by methods acceptable to them" (p. 78).

Using this definition, Penchansky and Thomas (1981) came up with the 5A's to conceptualize the dimensions of access. These are availability, accessibility, affordability, accommodation and acceptability. Firstly, they define availability as the relation between the number and category of existing resources to the number of population and their needs. Secondly, accessibility is the link between the location of the facilities and the location of the population while assessing the transport, time, travel cost and distance. Thirdly, affordability is the link between the costs of services and the ability of the users to pay for it. Fourthly, accommodation is the link between the providers' ease of accepting users and the users' ability to adjust to this and their view of its suitability. Lastly, acceptability is the link between the users' beliefs about the providers' behaviour and the real behaviour of the providers and vice versa. The five dimensions are closely linked which explains why they form part of the concept of access (ibid). However, this research will use the first three dimensions to define access due to limitation of method of data collection on the other two dimensions.

The Centre for Health and Economics Research (1993), observed the need to have indicators to define access to health care. The subsequent section will concentrate on the indicators of the three dimensions. 


\subsubsection{Availability}

Penchansky and Thomas (1981) suggest three indicators of availability: the supply of health workforce, health facilities and specialized programs such as emergency care and mental health. Social Protection Committee (2013) adds that availability is measured by the number of health workforce with the correct skill mix to match people's needs and the supply of medicine and equipment as well as access to pharmacies (Campbell et al., 2000). Gulliford et al (2002), adds that bed capacity is an important indicator. Other Scholars (Donabedian, 1972) have however raised concern that availability is not enough to measure access because of financial or organizational obstacles, which could hinder one from accessing available services. Gulliford et al. (2002) posit that access largely depends on physical accessibility and affordability.

\subsubsection{Accessibility}

WHO defines the indicator of accessibility as the geographical distribution of health facilities and the ease of reaching them. Penchansky and Thomas (1981) note that in some cases, accessibility and availability are treated as one.

\subsubsection{Affordability}

Shrestha (2010) argues that there may be adequate supply of facilities and staff close to the people but they may not be affordable. In such scenarios, people tend to move to other areas in search of affordable services. Therefore, it is important to take account of the affordability aspect. This dimension includes indicators such as the percentage of population insured, the existence of subsidized programs for some groups and the percentage of out of pocket expenditure as a total of private expenditure on health (IOM, 1993).

\subsection{Conceptual Framework}

With this in mind, this research contributes to the discourse by conducting an empirical study centred on the overall research question; has devolution improved provision of health services in Kenya? The research strategy is to address this question based on a conceptual model that links devolution to increased access to primary and secondary health services. 
Figure 1 shows the conceptual framework

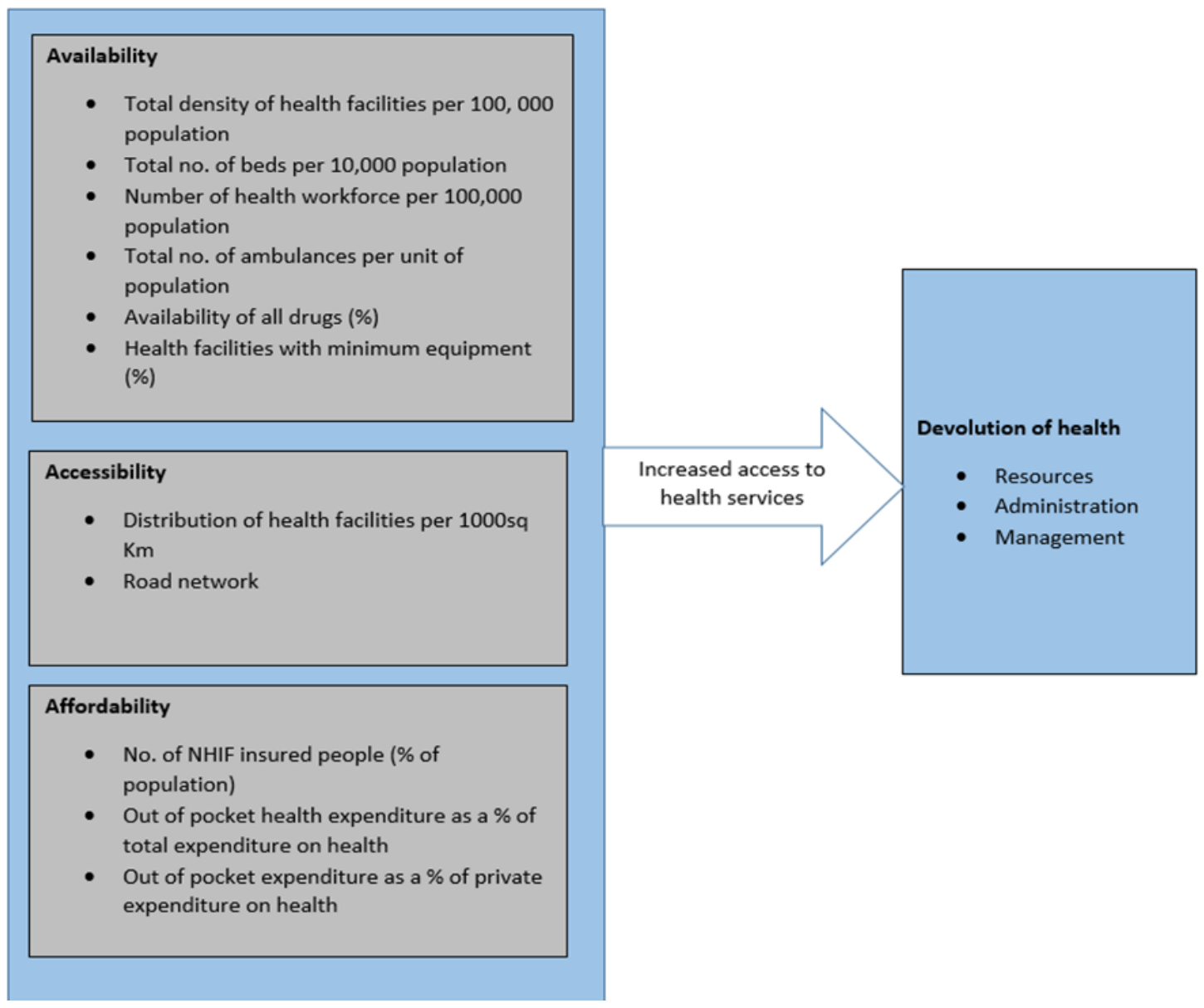

Figure 1: Conceptual Framework

The model is based on Penchansky and Thomas (1981) 5 A's. This provides a structure that helps with data collection as well as conceptual view of analysing the data collected. The access is measured by availability, accessibility and affordability. The indicators of devolution are ownership of health facilities by counties, allocation of health resources responsibilities and procurement powers by county governments. This section has defined the concept of access and outlined this research's conceptual framework. The next section will now delve into the debate on health decentralization.

\subsection{Health Decentralization}

Decentralization has been promoted by international donors as a sectoral reform in health with the objective of improving efficiency, suitability of health programs to community needs and conditions and improving accountability to the community (Collins \& Green, 1994; Bossert et al, 2003; Jimenez \& Smith, 2005). The Alma-Ata Declaration (1978) states 
that decentralization is necessary for the attainment of primary health care. Undoubtedly, the ultimate goal of any health care system is to meet the health needs in their society (Collins \& Green, 1994). This therefore makes decentralization a pre-requisite for achieving this (ibid). A key argument for decentralization in the health sector is that it facilitates access to the public goods and services, brings less privileged groups closer to services, responds faster to health needs of a community and helps coordinate activities among different sectors that deal with the wide array of determinants of health (Conyers, 1983). The World Bank (1987) correctly uses the inequities in many developing countries' health systems as justification for pushing for decentralization.

However, there are dissenting views on the impact of decentralization on health. A recent literature review on the effects of health decentralization in Asia carried out by Ghuman and Singh (2013) confirms this by giving examples of empirical studies showing positive and negative results of decentralization.

Despite the mixed results, the case for centralization is stronger. In his analysis, Robinson (2007) concludes that healthcare has worsened under decentralization in six Latin American countries and in African countries such as Nigeria. Others argue that decentralization can lead to health inequities (Collins \& Green, 1994; Prud'homme, 1995; Jimenez \& Smith, 2005) Bossert et al, (2003) demonstrate that decentralization would further marginalize poor areas that are not able to fund their services while richer areas would be able to get better services. They point out that centralized systems are most likely to redistribute resources in favour of the poor (ibid). Faguet (2001) disputes this in his study carried out in Bolivia. He posits that it is in fact centralization which might lead to some regions being marginalized (ibid).

Still, there are decentralization problems such as lack of capacity at sub-national levels. Moreover, some public goods for example medical training are national goods that if decentralized generates inefficiency (Magnussen et al, 2007). But economists such as Gravelle (2003) argue that centralisation is relevant for health as it prevents inefficient location of health facilities by local decision makers accountable to local electorate. Other arguments put forth is that the central ministry is more efficient in bargaining for better contracts with service providers (Mitchell \& Bossert, 2010), guarantees a similar level of 
health care services and does not increase user fees to finance their services (Jimenez \& Smith, 2005).

From the above discussion, as Mitchell and Bossert (2010) put it, it seems that decentralization is not the right thing to do in a health system. However, it is misleading to conclude this as often decentralization and centralization are implemented in different time periods (Bustamante, 2010). Collins and Green (1994) suggest that primary health care decision-makers should analyse their countries' political context and ramifications of decentralization policy before adopting it as a panacea to their health challenges. This next section is therefore going to discuss Kenya's context of decentralization which is devolution and its devolved health sector.

\subsection{Devolution in Kenya}

As defined earlier, Devolution is the creation of autonomous and independent units of government that have clear and legally recognized boundaries within which they exercise their power and perform their functions (Rondinelli, 1981). Kenya is one of the few countries that have fully devolved its political, fiscal and administrative powers.

Kenya's General Elections in 2013 saw a shift from the centralised government to a devolved county government system. This followed the adoption of the 2010 constitution that introduced a 'framework of governance with a national government and 47 counties' (Barker et al, 2010) from a previous system that had 280 districts (Nyikuri et al, 2015). World Bank (2012) points out that, Kenya's devolution is one of the most ambitious forms of decentralization to be implemented globally.

Historically, Kenya had a form of decentralization called majimbo (devolution) which accorded eight regions with serious authority (Anderson, 2005; Kibua \& Mwabu, 2008). However, this was stopped by the newly independent government's constitutional amendments in 1964 (Burugu, 2010). Lynch (2011) argues that the Kenya African National Union (KANU)-ruling party-leaders only agreed to majimbo plans so as to accelerate independence. This meant that in 1964, the KANU government was highly centralized with all the powers sitting in the capital city, Nairobi (Kubai, 2015). The previously devolved regions were reverted to the central government and became known as provinces (Kibua \& Mwabu, 2008). 
Nevertheless, the government adopted the Sessional Paper No. 10 on African Socialism and its Application to Kenya of 1965 which sought to bring development planning closer to the people (ibid). Hence, it is unsurprising that in 1983, the new president, Daniel Arap Moi, deconcentrated administrative powers to provincial commissioners and district commissioners through the District Focus for Rural Development (DFRD) (ibid; Cheeseman et al., 2016). But Boone (2003) and Lynch (2011) argue that this was an attempt by the President to legitimise his power through decentralization.

Indeed, in the early 1990s, there were calls for further decentralization of resources and services by the public and civil societies (Kubai, 2015). The KANU leadership responded by reviving the idea of majimboism which however, did not result in any real decentralization of powers (Lynch, 2011). Rather, the advocacy paid off in 2002 when a new government, National Rainbow Coalition (NARC), introduced the Constituency Development Fund (CDF) which transfers resources to lower levels of government called constituencies (Cheeseman et al., 2016). The CDF Act requires government to allocate $2.5 \%$ of its revenue to 290 constituencies run by MPs (Ntuala, 2010). It is for this reason that Cheeseman et al. (2016) notes Kenya emerges as one of the highly-decentralised countries in Africa in Ndegwa's (2002) analysis of decentralization in Africa.

According to Cheeseman et al. (2016), there are three factors that led to the 2013 devolution of administrative, fiscal and political powers in Kenya. One, there was a long history of demand for decentralization. Secondly, the $2007 / 8$ post-election violence led to calls for a decentralized system as one of the solutions to the ethnic tensions in the country and lastly, the government needed political legitimacy and thus agreed to a new constitution whose draft passed the referendum with a $68.5 \%$ yes vote on $4^{\text {th }}$ August, 2010 .

Kenya settled on full devolution with a relatively high degree of transfer of authority, responsibilities, power and accountability to the county governments (KPMG, 2013). Murkomen (2012) argues that unlike Ethiopia and Nigeria that emphasise self-government, Kenya chose a symbiotic system of devolution where the principle of interdependence of the government units prevails. Kenya's devolution is characterised by distinct boundaries, taxation powers, allocation of functions and resources to counties, intergovernmental relations and constitutional protection (ibid). See figure 2 below for the structure of the devolution. 


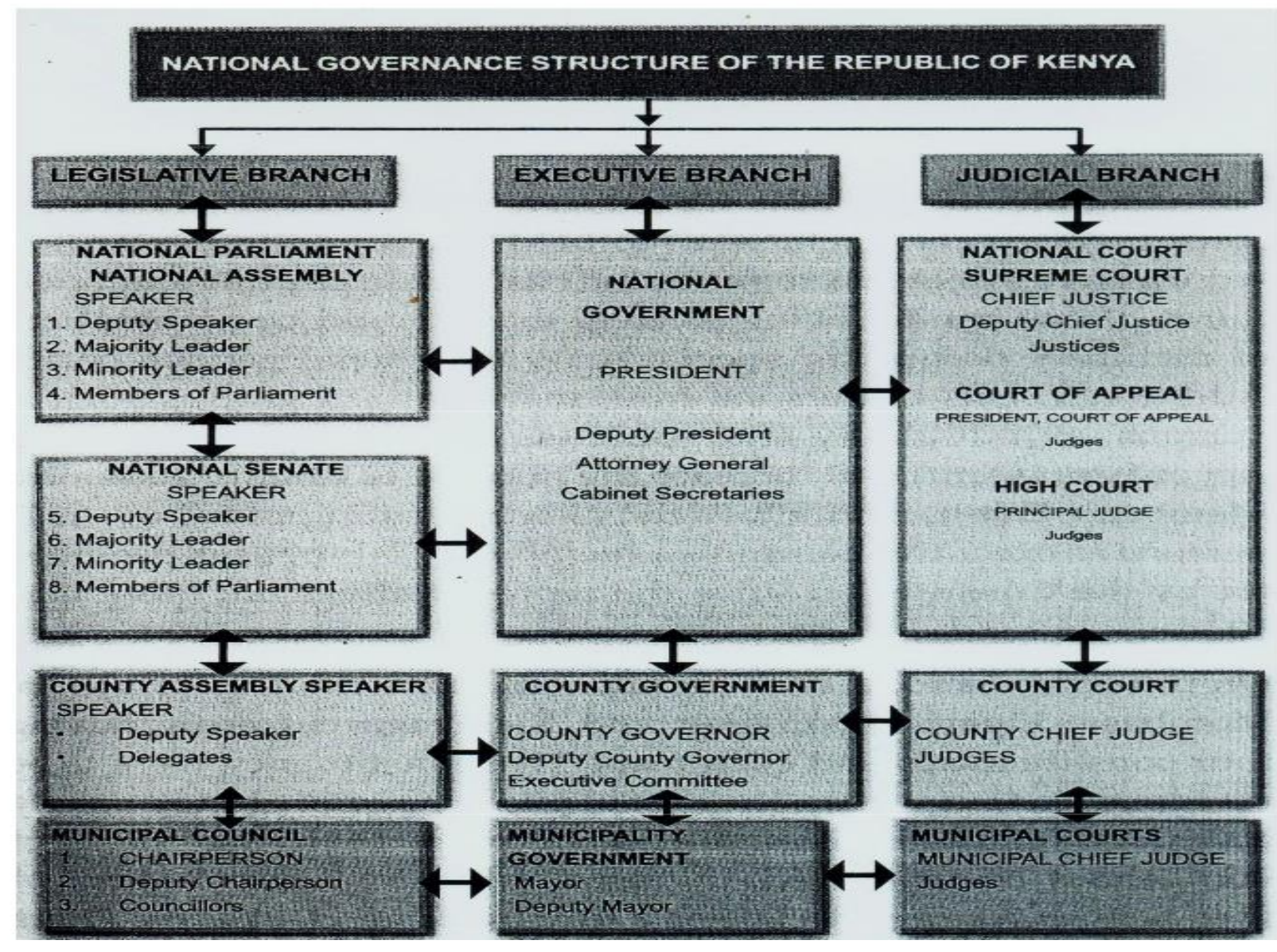

Figure 2a: Structure of Kenya's Devolution (Burugu et al, 2010)

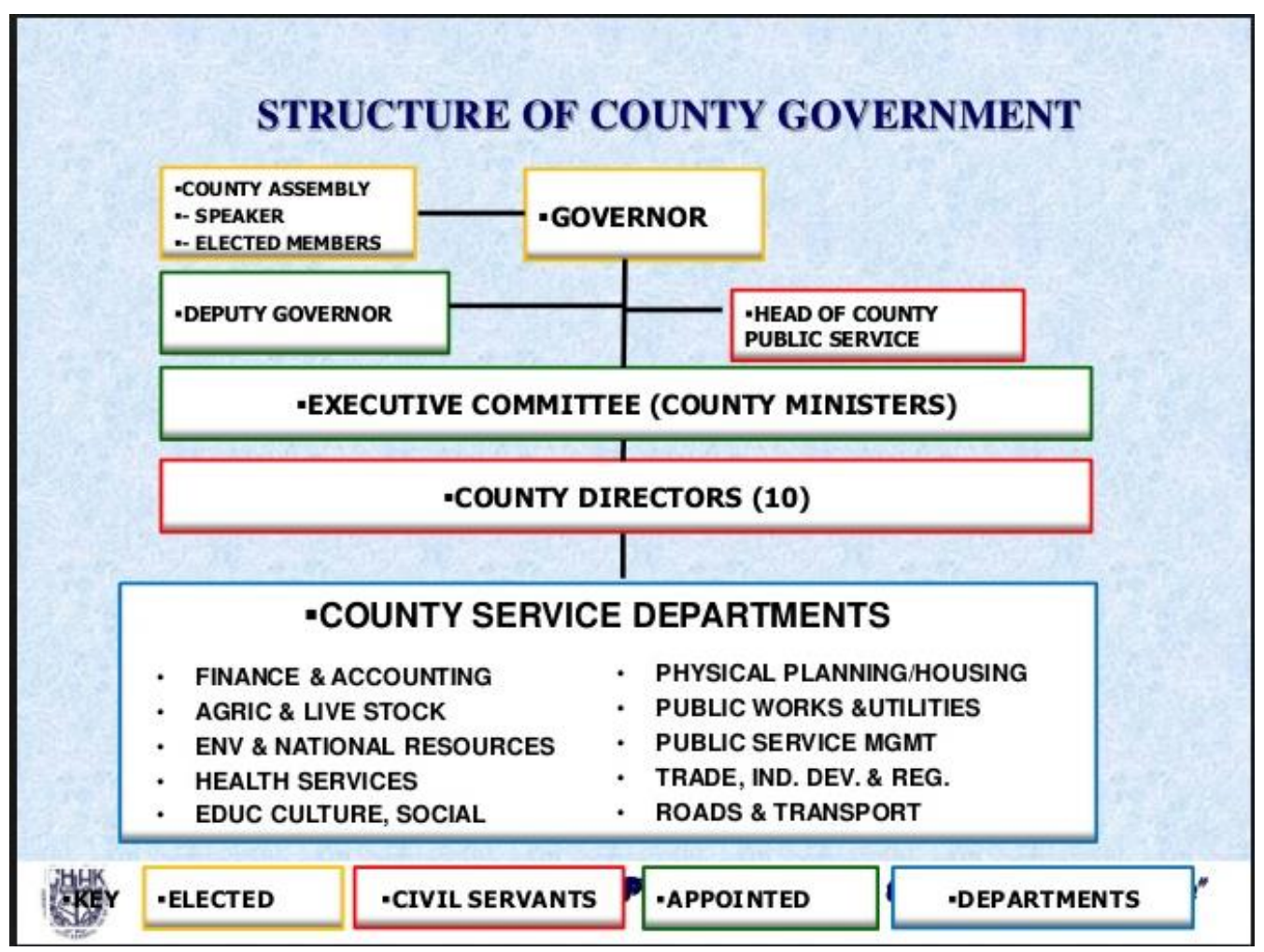

Figure 2b: County Government Structure (CRA, 2017) 
The county Government has two main structures which are the County Executive and Assembly. While the National Government has two houses; the National Assembly and the Senate, the County government has only one, the Assembly.

The Assembly is made up of members of County Assembly elected from each ward within the county. The Executive is made up of the County Governor who is elected, and the people appointed by the Governor subject to approval by the County Assembly. The County Public Service Board is made up of civil servants seconded by the National Government and is responsible for all human resource functions in the County. The County Directors are civil servants seconded by the County Public Service board.

The Fourth Schedule of the constitution establishes the functions of the county government See figure 3 for the functions of county government.

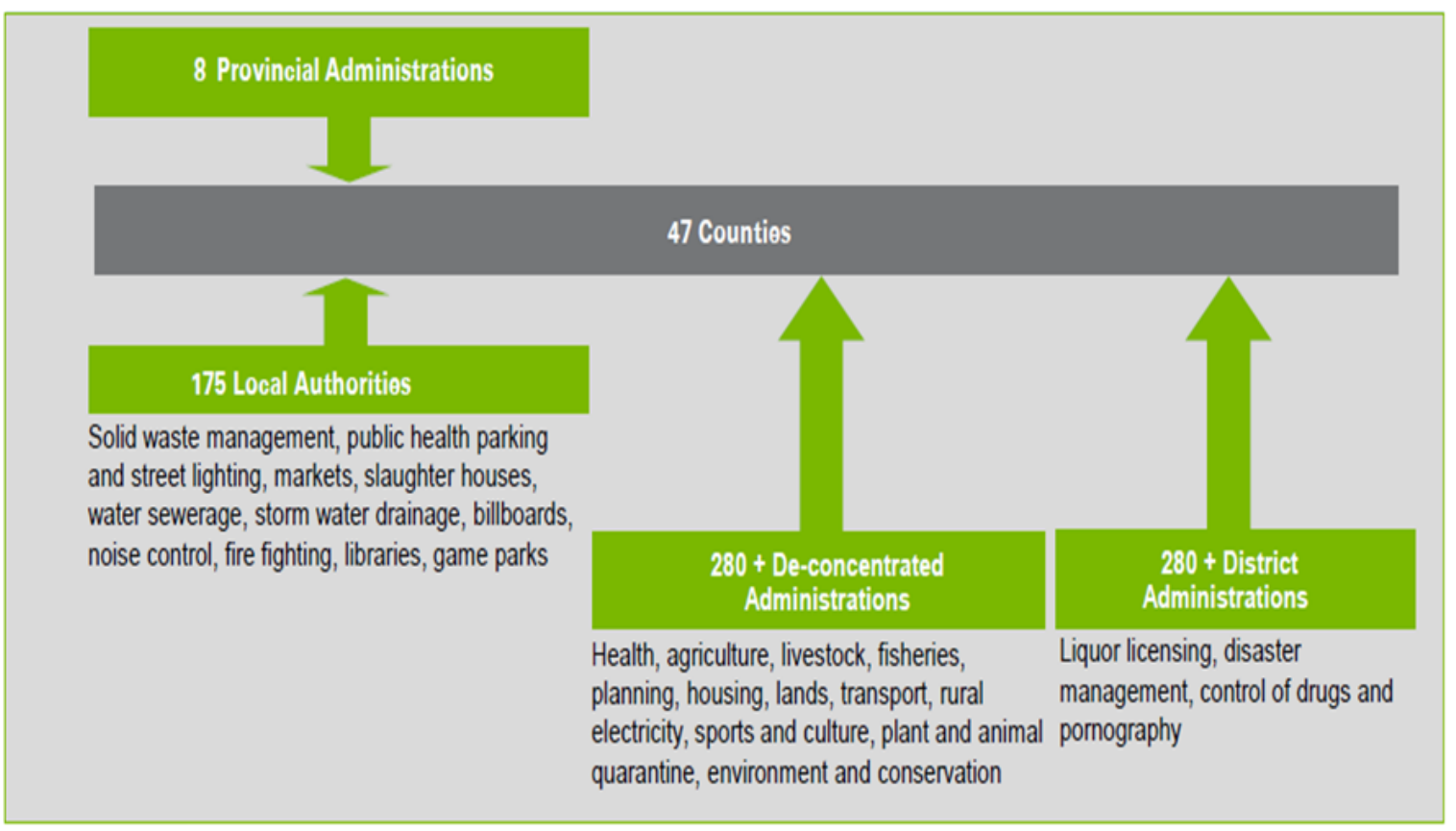

Figure 3: Functions of the County Governments (KPMG, 2013)

Before devolution, there were eight provincial administrations which had considerable power through which the central government administered its rule. Under the eight provincial administrations were 280 district administrations that acted as local governments but were only responsible for licensing, regulation and responding to disaster within the district physical boundaries. Under these district administrations were 175 local authorities which were known as municipal councils and were responsible for operations that generated revenue for the council. 
The Constitution (2010) saw the collapse of all these administrations into County governments. The 47 county governments now undertake all the responsibilities of the district administrations and the local authorities. They also have more power than the previous provincial administrations and greater autonomy and legitimacy.

Having discussed the process of devolution in Kenya, the following section will look at the devolved health system.

\subsection{Devolution of Health Sector in Kenya}

The Kenyan health sector has been undergoing reforms for many years and thus it is characterised by many policies including the Kenya Vision 2030 (Chen et al, 2014; Tsofa et al, 2016). In 1965, the KANU government first introduced the concept of Free Health Care for All that abolished user fees at all local public clinics (Oyaya \& Rifkin, 2003). Five years later, the health system was nationalized and the concept was expanded to all public health facilities. In the subsequent years, Kenya adopted the 1977 World Health Assembly (WHA)'s Health for All by the year 2000, the 1981 Global Strategy for Health for all by the year 2000 and the 1978 Alma- Ata Declaration on PHC. Consequently, Kenya published the National Guidelines for the Implementation of Primary Health Care in Kenya in 1986, which was based on the principle of decentralization (ibid). This saw the creation of District Health Management Boards in 1992 by the $\mathrm{MoH}$ to ensure funds reached the local units (Kenyan Healthcare Sector, 2016). Further policies were published: the 1994 Kenya Health Policy Framework and Kenya Health Strategy Paper following the World Development Report (1993) on investing in health. All these policies had a common agenda; to bring health services closer to the people.

The 1994 Kenya Health Policy Framework aimed at ensuring Kenyans had decent, cheap, quality and reachable healthcare by 2010 . The policy was implemented through two plans; National Health Sector Strategic Plan 1994-2004 and 2005-2010. The plans set out the organization of public health system with the national referral hospitals at the top, followed by provincial hospitals, district health centres and village dispensaries at the bottom of the pyramid. However, in 2010, the new constitution devolved the function of primary and secondary health service delivery to the 47 counties (Constitution, 2010). This followed 'a 
special issue 1795 of the Kenya Gazette Supplement No. 116 Legislative Supplement No. 51 legal notice no. 137' (Mwamuye \& Nyamu, 2014).

Kenya's health sector devolution is fiscal and administrative with a high degree of autonomy in budget allocations (Kenya Health Sector, 2016). Under devolution, health service provision and ownership of health facilities is managed by the counties while the national government's responsibilities is limited to policy making, managing the national referral hospitals, providing technical advice to the counties and regulation (Nyikuri et al, 2015). In addition to these changes, following a Presidential directive (Daily Nation, 2013), all user fees and maternal fees were removed from public primary level facilities and public facilities respectively. Figure 4 shows the national ministry and county governments' responsibilities for health.

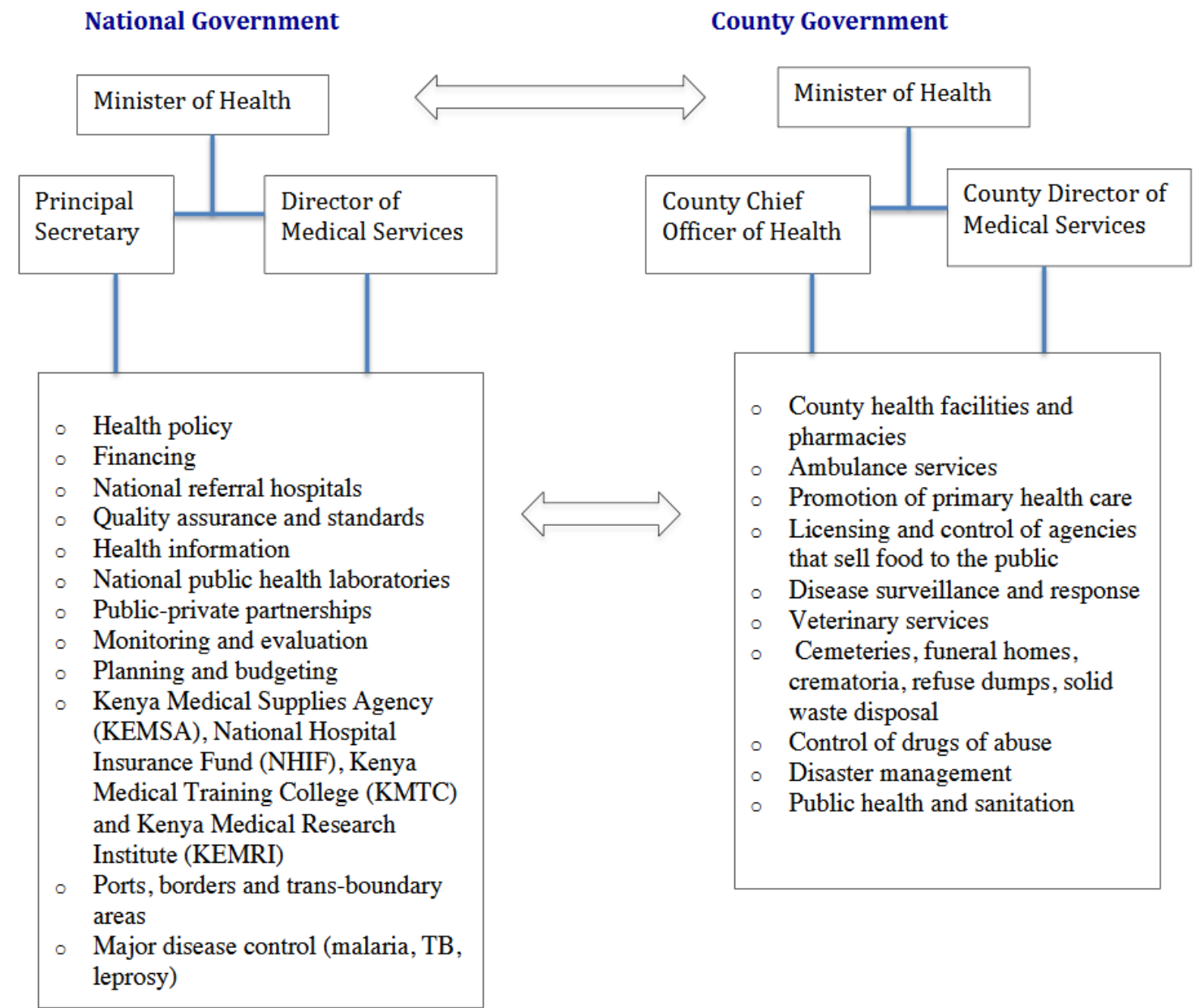

Figure 4: Separation of Responsibilities for Health (Kenya Health Policy 2014-2030) 
Before devolution, Kenya's health sector was organised on three levels; MoH headquarters, Provincial Health Management Teams (PHMTs) and District Health Management Team (DHMTs) (Tsofa et al., 2016). Health services were delivered through community units, dispensaries, health centres, district hospitals, provincial hospitals and national hospitals $(\mathrm{MoH}, 2007)$. Now, each county governs its own health system with authority over resource allocation, remuneration for health workforce, maintaining and/or building new health facilities and procuring medical equipment and drugs (Kenya Healthcare Sector, 2016). The counties have introduced a County Health Management Team and Sub-County Health Management Team which Nyikuri et al., (2015) argue replace the previous PHMTs and DHMTs. The primary health care facilities are classified as level 2 in the current county health system organization. See figure 5 below.

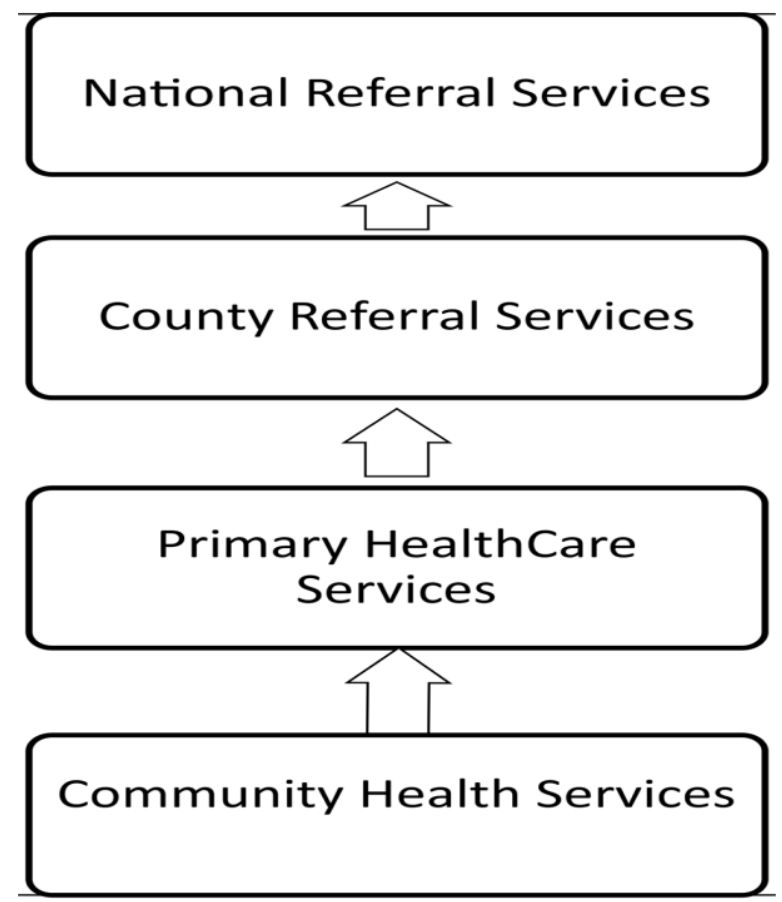

Figure 5: Kenya's Devolved Health System Hierarchy (Nyikuri et al, 2015)

The community health services constitutes of all community based demand generated actions or cases identified for referral. The primary healthcare services comprises of all dispensaries, health centres and maternity hospitals for both public and private suppliers. The county referral services include hospitals operating in and managed by the counties and are basically former level 4 and district hospitals existing in the county prior to devolution. National referral services carry out extensive and specialised services and include all tertiary 
referral hospitals (KPMG, 2013). These are; Kenyatta National Hospital, National Spinal Injury Hospital and the Mathari Teaching and Referral Hospital all in Nairobi, Moi Teaching and Referral Hospital in Uasin Gishu County and Jaramogi Oginga Odinga Teaching and Referral Hospital in Kisumu County. (Kenya Healthcare Sector, 2016). Only the National Referral services are under the national government responsibility (Kenya Health Policy, 2012). This next section presents the summary of the literature review.

\subsection{Summary}

The literature review has analysed the concepts, issues and debate about decentralization and its impact on provision of health services. The impact of decentralization on access to health services is at most mixed but tends to lean more on the negative side. There is a suggestion that decentralization policies only work in countries that have the following conditions: political commitment, capacity among local governments, adequate allocation of resources and willingness of the central bureaucracies to let go. The next chapter will outline the systematic procedures of collecting and analysing data, used for this study. 


\section{Methodology}

In the literature reviewed, there was uncertainty on the impact of decentralization on health. This study sought to add to the discourse by examining the impact of Kenya's devolution on access to health services. This section therefore presents the systematic process that was used to carry out the research. It begins by discussing the research strategy, design and the philosophy adopted. A discussion then follows on the methods of data collection and the choice of data analysis method. Finally, it appreciates the limitations of the research.

\subsection{Research Strategy \& Design}

This study adopted a deductive approach. It sought to test the assumptions that decentralization leads to increased access to health services. It follows a case study design. Yin (2009) defines a case study as

"An empirical inquiry about a contemporary phenomenon...set within its real world context especially when the boundaries between phenomenon and context are not clearly evident" (p. 18).

The nature of the case study is explanatory (De Vaus, 2001) as it tries to explain how devolution has affected access to health services. Yin (2012) argues that this is an appropriate design for research addressing the descriptive ('what 'or 'has') and explanatory ('how' or 'why') questions. An alternative could be to use the experiment design but this would not give an insightful examination of case studies. Another advantage of the case study is the acknowledgement of use of multiple sources of data that allow for triangulation (Burns, 2000). Nevertheless, there are concerns over its generalization, validity, reliability and rigour. To overcome these problems, the researcher uses multiple sources of evidence and employs a comparative case study analysis to other empirical studies for rigour. Comparison of case studies also help to prove generalization (Dopson, 2003). The research generalizes the findings to the theory and not the statistical population (Flick, 2011).

\subsection{Research Philosophy}


The approach taken is positivist. Neuman (1994) explains that positivism is usually associated with deductive strategy where data is collected to test a theory. He argues that this often goes along with quantitative data (ibid). However, quantitative data is not able to pick up the social perspectives of people (Yin, 2009) and therefore this was one of the limitations of this research.

\subsection{Sources of data}

Case studies allow for a wide range of data collection methods (De Vaus, 2001). This is a desk-based research that uses secondary quantitative data which is consistent with the positivist approach (Denscombe, 2014). However, since this is a case study research, it additionally employs documentary data. This mixed methods approach allows for triangulation (Dale et al, 1988), provides a complete picture (Denscombe, 2014) and is essential for the study (May, 2011).

The secondary quantitative data was gathered from Kenya's government publications and official statistics. The sources included Ministry of Health, Kenya; County government websites; Commission on Revenue Allocation; Kenya Open Data portal and Kenya National Bureau of Statistics. These are credible, objective and factual (Denscombe, 2014) sources of data. Also, May (2011) adds that they provide a rich dataset since they carry out large surveys. Still, some authors (Dale et al, 1988) caution on this as the data presented may be trying to represent a false success or with a political undertone. To reduce this, the secondary quantitative data also drew from the data repositories of international development agencies such as the World Bank, World Health Organization and USAID's Health Policy Project.

The documentary data was collected from government press releases, news stories, and government officials' public speeches. Documentary data is argued to be readily available and socially constructed and thus useful to triangulate data (Mathews \& Ross, 2010). However, they suffer from change of definitions. This was corrected by the other sources of evidence.

The data selection was based on a criterion identified by the researcher. An internet search and library catalogue was run during the initial phase in June for both literature review and case study material. The protocol established looked though databases such as ProQuest, 
Wiley, PubMed, Commonwealth Journal, Google Scholar, Web of Science, World bank data portal, WHO data, Ministry of Health-Kenya website, County Government of Makueni and Kisumu websites and University of Nairobi repository. The key words used in the search strategy included "Kenya", "Developing Countries", "Decentralization", "Devolution", "Counties", "Health" "Healthcare" and "Access to healthcare".

To ensure manageable data for the case study, limits were applied to the search for the period 2010-2016 for national data and 2013-2016 for county data. This was categorically chosen to show the situation pre-devolution and post-devolution.

\subsection{Choice of data analysis method}

The secondary quantitative data extracted was analysed using descriptive statistics and was presented using bar graphs and pie charts. As the dataset was not large, the study could not disaggregate results according to background characteristics such as county. Thus, this study presented only percentages in the analysis. Moreover, pattern matching (Yin, 2012) was used to compare post trends in the counties with those of the national government as well as between Kenya and a few other countries that have been studied. The study used the existing literature to explore rival explanations for changes noted. This as Yin (2012) posits, reinforces the results.

\subsection{Limitations of the research}

As with any research, this study encountered some challenges. To begin with, this was a desk-based study that means it relied on secondary data. Most developing countries suffer from lack of data especially on health inputs (Khaleighan, 2003). Consequently, gaining access to data particularly the County data was difficult and as a result, a lot of time was spent trying to access this data. Although access was granted, a lot of the available data was found not relevant to the research objectives. Moreover, as secondary data is often produced for other purposes (Denscombe, 2014), this meant more time spent to critically examine the sources of relevant data. There were a lot of contradictions on not only the statistics of access to healthcare indicators but of basic social indicators such as population. Still, the researcher was able to find substantive national and two counties' data that covered for the insufficient, irrelevant and at times disparate quantitative counties' data. 
Having discussed the research methodology, this research will now introduce the socioeconomic background of Kenya and then shift to presenting the findings and discussing the ramifications both in Kenya's context and the wider discourse. 


\section{Kenya's Background}

A former British colony, Kenya is the largest economy in the Eastern part of Africa (KNBS, 2017) with a population of $48,461,567$ (World Bank, 2016). Historically, it has had political developments that saw the move from one-party state to multiparty state in 1992. However, this only resulted to ethnic clashes every election year save for 2002 , when a new government was formed ending the 41- year rule by KANU (Lynch, 2011). Scholars (Mutua, 2008; Lynch, 2011; Cheeseman et al., 2016) have argued that the clashes witnessed every election period are a consequence of the country's long standing marginalization of not only peripheral areas to Nairobi but also areas that support opposition. Therefore, the 2010 constitution that introduced devolution was welcomed by the population who view it as a system that reduces the 'winner takes it all' politics.

Administratively, the country has 47 counties divided along 582,646 square kilometres. About $80 \%$ of the land area is arid and semi-arid explaining the disparities of population density in the country (KNBS, 2014). While there's been an influx of people moving to urban cities from the rural areas, there is still about $74 \%$ of the population living in rural areas (World Bank, 2016b).

Kenya has a large middle class constituting $45 \%$ of the population. This middle class is increasingly demanding for better quality healthcare. (Kenya Healthcare Sector, 2016) However, there is a high level of health inequality depending on where you live (Diop et al., 2014) as shown in figure 6 below. 


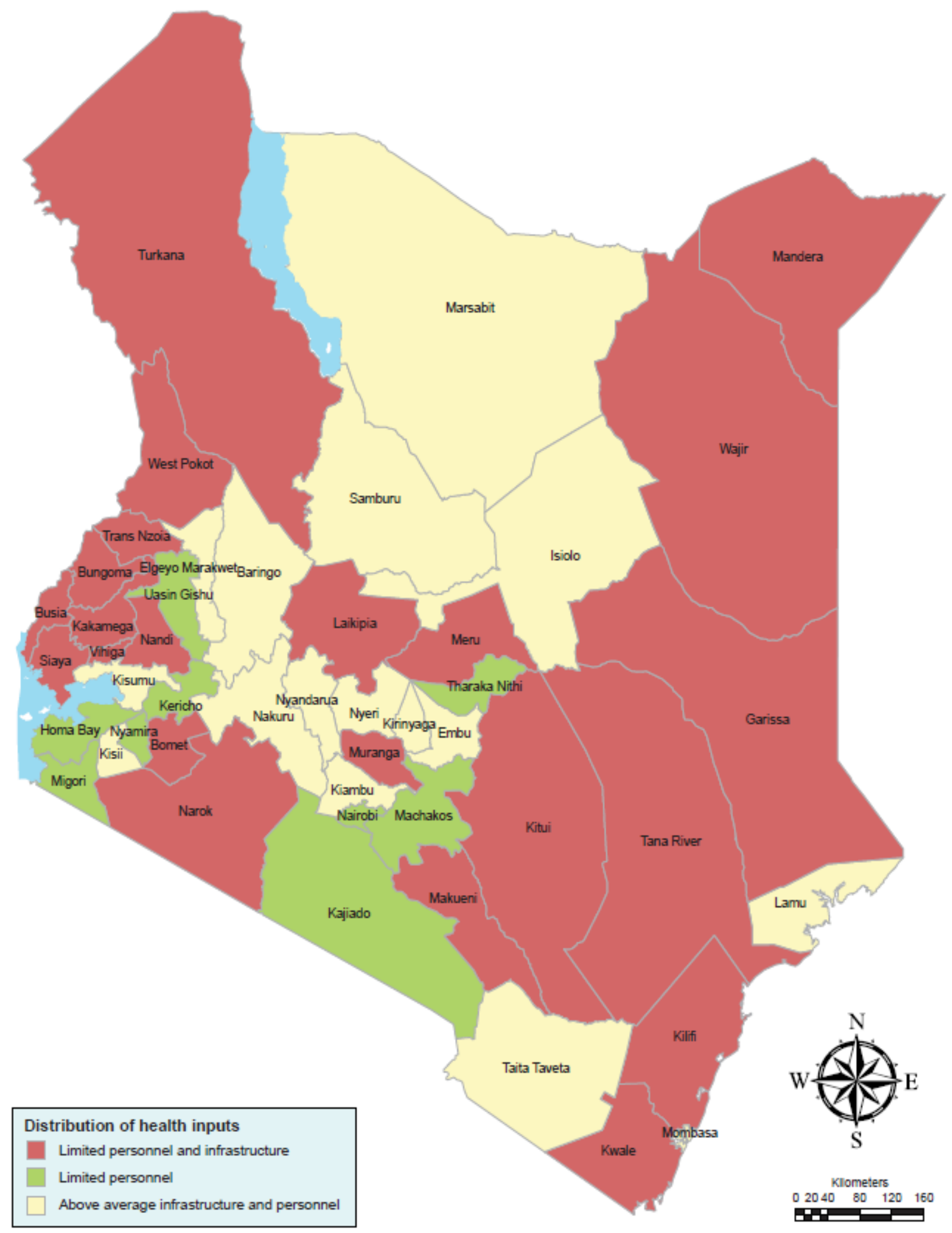

Figure 6: Distribution of Health Inputs among Kenya's 47 Counties (Kenya Health Expenditure Review, 2014) 
Even though Kenya's life expectancy is 62 years, the disease burden of HIV/AIDS and the under-five mortality rate are still high. HIV/AIDS is the second most common disease $(14.8 \%)$ that causes death in the country after malaria $(27.7 \%)(\mathrm{MoH}, 2016)$. According to a Global Burden of Disease collaborative network study (Wang et al, 2016), whereas the country's prevalence of the disease has declined, a number of new infections are rising faster than in any other sub-Saharan Africa country.

To understand better the impact of devolution on access to healthcare services, the researcher chose two counties to give a comparative perspective. The counties are Kisumu and Makueni. The researcher chose these to represent the urban and rural populations respectively in Kenya. Kisumu has a share of $52.4 \%$ of the national urban population and is ranked at number 4 out of 47 counties while Makueni has a share of $12 \%$ of the national urban population and is ranked 42 out of 47 counties in total urban population (CRA, 2013). The successive sub-sections will give both counties' background.

\subsection{Kisumu County}

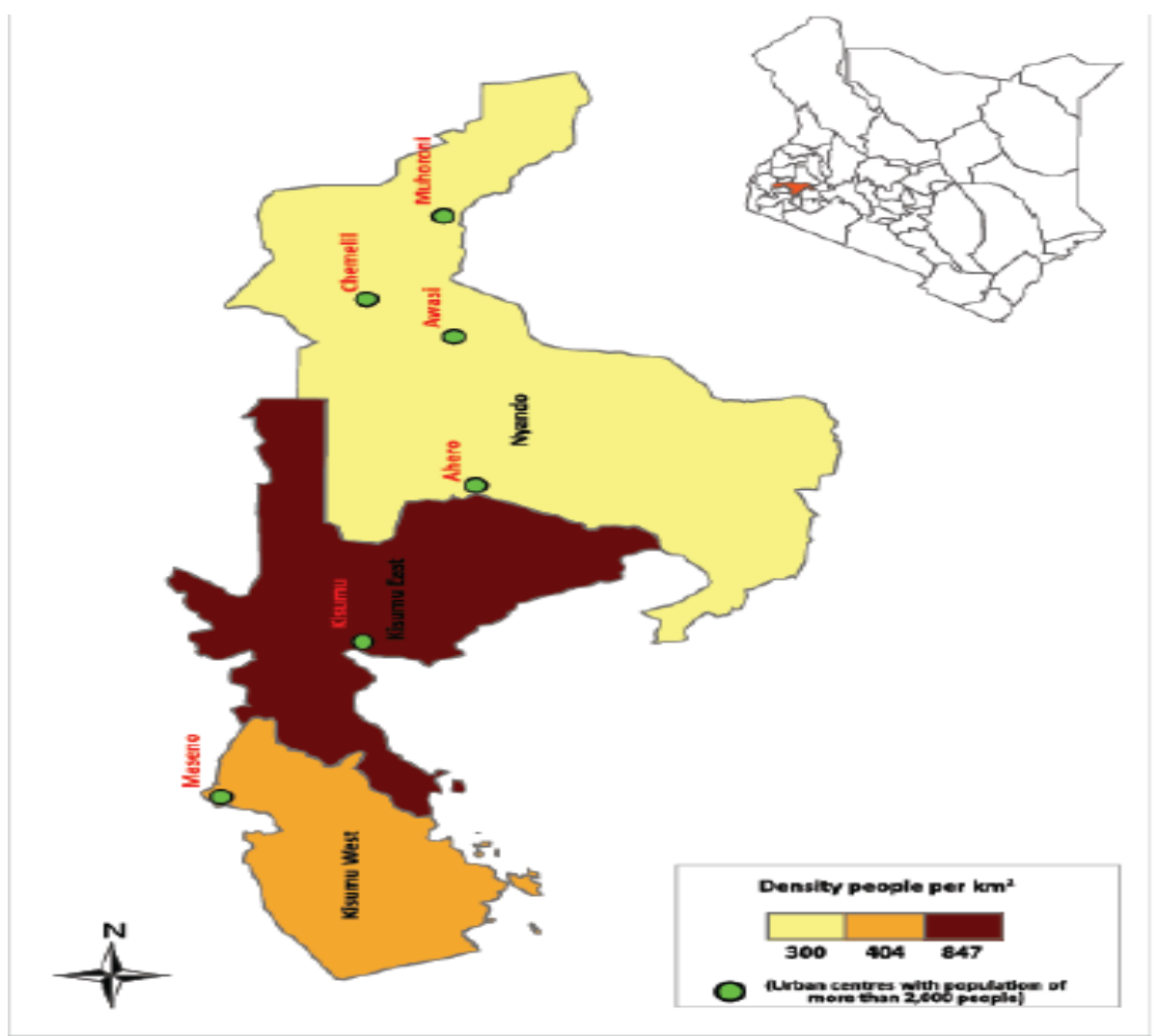

Figure 7: Administrative Boundaries of Kisumu County (HPP, 2013) 
Kisumu is located in the western part of Kenya. It is bordered by Homa Bay County to the South, Kericho County to the East, Nandi County to the North East, Siaya County to the West and Vihiga County to the North West. (County Government of Kisumu, 2013).

It covers an area of 2086 sq.km with a population of 1,107,755 people (KNBS, 2016). This means it is a high dense area of 531 people per sq. km compared to Kenya's 76 people per sq.km (KNBS, 2016). The HIV rate in the county is the third highest in the country at $19.3 \%$ against national's rate of $5.9 \%(\mathrm{MoH}, 2016 \mathrm{~b})$. This burdens the County Government's resources. The under-five mortality rate is also high at 79 deaths per 1000 live births (County Government of Kisumu, 2016a) compared to Kenya's average of 49.4/1000 live births. The life expectancy at 59.5 years (Ibid) is also below the national average of 62 years (World Bank data, 2015). Only 53.6\% of children are immunized against Kenya's average at $67.5 \%$ (KNBS, 2017). Another major disease burden in the county is malaria at $36.6 \%$ against Kenya's $27.7 \%$ due to the proximity to Lake Victoria (HPP, 2013).

About $60 \%$ of the population live in absolute poverty (KNBS, 2016). Kisumu is also prone to political violence (CRA, 2013). This has increased the population's view of marginalization by the national government because of supporting the opposition. Despite this, Kisumu is one of the counties that have better health inputs compared to other counties in the country such as Makueni as shown in figure 6 above.

\subsection{Makueni County}




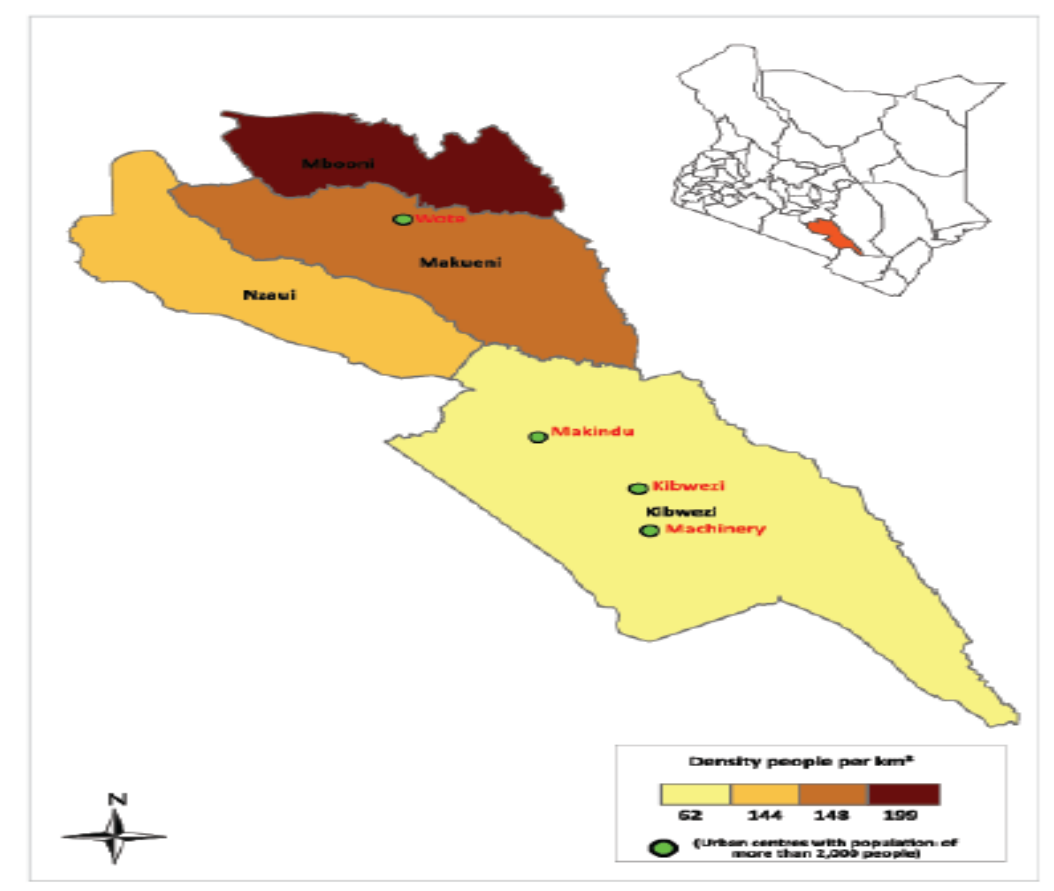

Figure 8: Administrative Boundaries of Makueni County (HPP, 2013)

Makueni is located in the south eastern part of the country with an estimated area of 8,008.8sq.km. It boarders Machakos County to the North, Kitui County to the East, Kajiado County to the West and Taita Taveta County to the South (County Government of Makueni, 2015b). With a population of 949,298 people, it is highly sparse with a population density of 119 people per sq.km (KNBS, 2016).

However, it is largely an arid and semi-arid area and is often prone to droughts. The harsh weather conditions result in water scarcity problems. This means sanitation in the area is an issue with only $56 \%$ being able to access improved sanitation (County Government of Makueni, 2013). A major disease burden is malaria at $51.1 \%$ which is way above Kenya's average of $27.7 \%$ (HPP, 2013). Only $62.6 \%$ of children are fully immunised with an under 5 mortality rate of 56/1000 live births above Kenya's average. The life expectancy is also lower than Kenya's at 57.4 years (County Government of Makueni, 2016a).

In addition, it has a very high poverty rate at $60.6 \%$ against Kenya's average of $46 \%$ (KNBS, 2014). According to the County Government (2016a), the county has been marginalized since independence. Indeed, it has some of the worst road networks in the country with only $0.9 \%$ of the roads being paved compared to Kenya's 9.4\% (HPP, 2013). This poses a major challenge to accessibility of health facilities. 
Below is Table 1 summarising the profiles of the two counties and the national average

\begin{tabular}{|c|c|c|c|}
\hline & KISUMIU & MAKUENI & KENV A \\
\hline Population & $1,107,755$ & 949,298 & $48,461,567$ \\
\hline Area(sq.km) & 2,086 & $8,008.8$ & 582,646 \\
\hline $\begin{array}{l}\text { Population Densityl people } \\
\text { per sq.km) }\end{array}$ & 531 & 119 & 76 \\
\hline $\begin{array}{l}\text { Road network coverage (\% } \\
\text { of paved roads) }\end{array}$ & 4.9 & 0.9 & 9.4 \\
\hline Poverty rate (\%) & 60 & 60.6 & 46 \\
\hline Life Expectancy & 59.5 & 57.4 & 62 \\
\hline $\begin{array}{l}\text { Under five mortality( per } \\
1000 \text { live births) }\end{array}$ & 79 & 56 & 49.4 \\
\hline HIV Prevalence rate & 19.3 & 5.1 & 5.9 \\
\hline Malariarate & 36.6 & 51.5 & 27.7 \\
\hline Immunisation coverage (\$) & 53.6 & 62.6 & 80 \\
\hline
\end{tabular}

Source: worldbankdata.org; KNBS 2017; KNBS 2016; MoH 2016; County Government of Makueni 2016a; County Government of Kisumu, 2015a; County Government of Makueni 2015b; KNBS 2014; HPP 2013; CRA 2013; County Government of Kisumu, 2013; County Government of Makueni,2013

From the above table, there's a similarity of a few characteristics between the two counties. Their population total is alike. They both have lower life expectancy and higher poverty rate compared to Kenya's average. They also suffer heavy disease burden caused by HIV/AIDS and Malaria in Kisumu and Malaria in Makueni. The differences are noted in land mass, population density and road network coverage. While having comparable characteristics, the two counties also give an insight into the disparities between the urban and rural areas in Kenya. 


\section{Impact of Devolution on Access to Health Care in Kenya}

This chapter presents the findings of the effects of devolution on access to healthcare services in Kenya. The findings give a picture of the national data and county data using Kisumu and Makueni counties as representatives. In the findings, the period between 2010 and 2013 means pre-devolution while the period between 2013 and 2016 means post devolution. The evidence is divided under the availability, accessibility and affordability indicators in the immediate sub-sections.

\subsection{Availability}

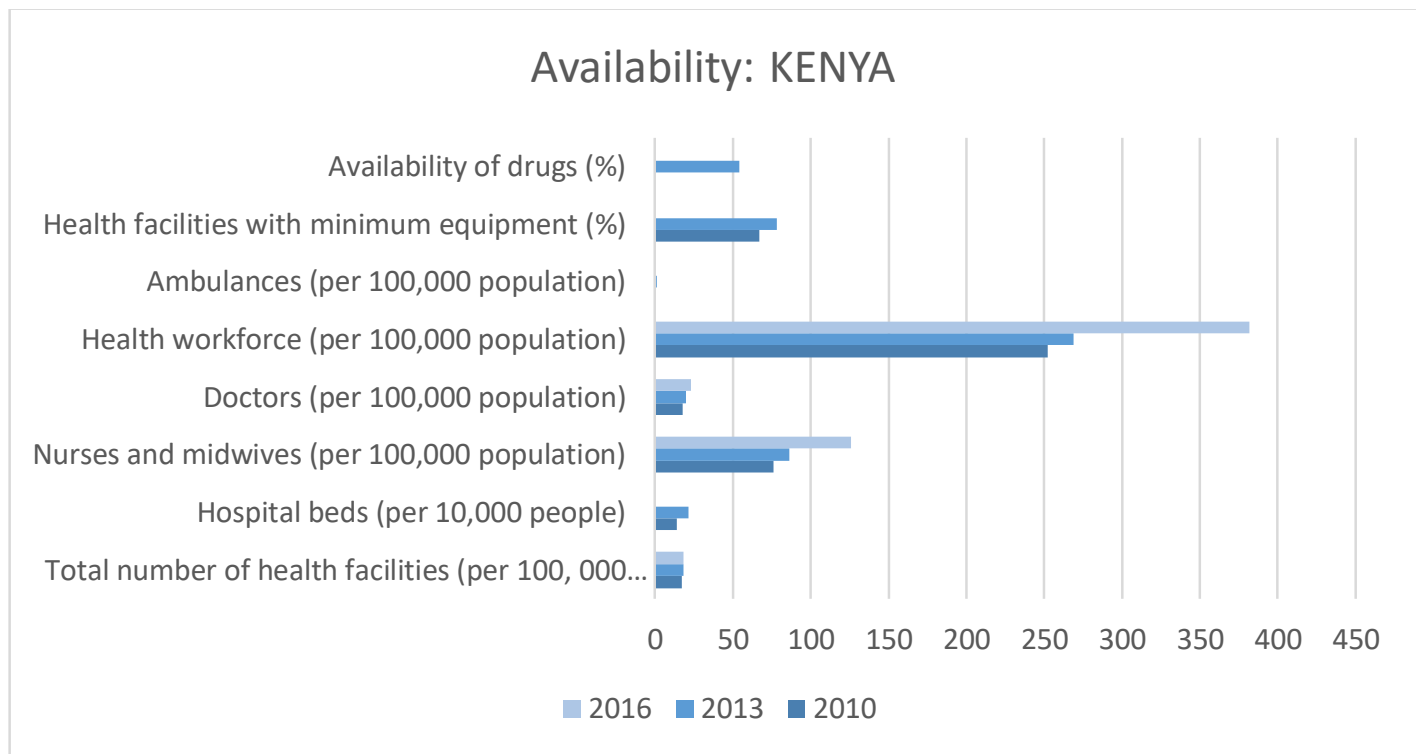

Figure 9: Availability of Health Services in Kenya between 2010 and 2016

Source: NCAPD et al.,2011; KNBS, 2011; MoH, 2013b; KNBS 2014; MoH, 2015; MoH, 2016; KNBS, 2016

The data observes that Kenya's availability of health workforce, facilities, infrastructure and products has shown an upward trend since 2010. Whereas the total density of health facilities increased in both periods, the pre-devolution period showed a bigger increase of $6 \%$ compared to post devolution period that only saw a slight increase of $1 \%$. $(\mathrm{MoH}, 2016)$. The SARAM report found that the total density of hospital beds increased by $50 \%$ from 14 beds per10,000 population in 2010 to 21 beds per 10,000 population in 2013 (MoH, 2013b). No reliable data was found on the density of hospital beds after 2013. 
There was a high absorption rate of health workforce after devolution (KNBS, 2014; 2016). While the health workforce increase rate in pre-devolution was only 7\% (KNBS, 2011) a steep trend was observed post devolution where health workforce increased by $42 \%$ from 269 workers per 100,000 population in 2013 to 382 per 100,000 in 2016 compared to the 252 workers per 100,000 population reported in 2010. (KNBS, 2014; 2016). The number of doctors in 2010 was 18 per100,000 population (NCAPD et al., 2011) compared to 23 doctors per 100,000 population in 2016 (KNBS, 2016). Likewise, the number of nurses increased from 76 per 100,000 population in 2010 (NCAPD et al., 2011) to 126 nurses per 100,000 in 2016 (KNBS, 2016). A remarkable increase was observed in the post devolution period which witnessed a $46 \%$ increase rate of nurses compared to pre-devolution's $13 \%$ increase rate.

The increase rate of ambulances was shockingly huge at $4983 \%$ between 2010 and 2013 (MoH, 2013b). Many of the ambulances were however acquired in 2013 by the County Governments (MoH, 2015). There was no conclusive data on the available ambulances post devolution. Lastly, health facilities with minimum equipment increased from $67 \%$ in 2010 (NCAPD et al., 2011) to 78\% in 2013 (MoH, 2013b). Similar to ambulances, there was no data on this indicator nor on availability of drugs after 2013 making it difficult to compare pre- and post devolution trends.

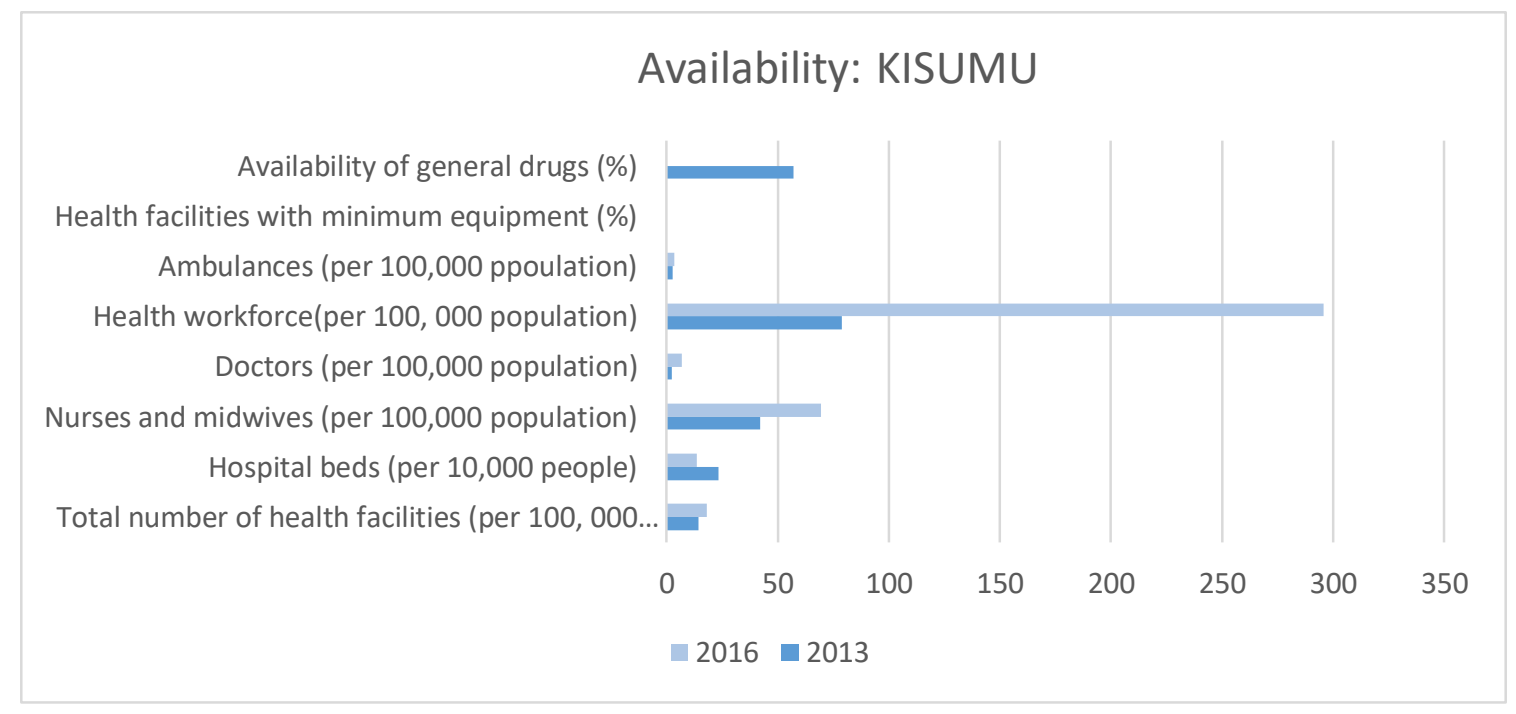

Figure 10: Availability of Health Services in Kisumu County between 2013 and 2016

Source: CRA, 2013; MoH, 2013b; County Government of Kisumu, 2013;2016a; KNBS, 2016; Kenya Open Data

Kisumu county's general availability of health services also increased between 2013 and 2016 with an exception of the hospital beds density. There was an increase of ambulances 
by $26 \%$ from 2.73 ambulances per 100,000 population in 2013 (County Government of Kisumu, 2013) to 3.43 ambulances per 100,000 population in 2016(County Government of Kisumu, 2016a). The number of health facilities also increased by $25 \%$ from 14 facilities per 100,000 population in 2013 (HPP, 2013) to 18 per 100,000 population in 2016 (KNBS, 2016). The most dramatic increase was the number of health workforce which quadrapuled from 79 workers per 100,000 population in 2013 (CRA, 2013) to 296 workers per 100,000 population in 2016(Kenya Open Data). The number of doctors particularly tripled from 2 doctors per 100,000 population in 2013 to 6 doctors per 100,000 population in 2016 while total number of nurses increased by 66\% between 2013 and 2016.

A sharp downward trend was however observed in the hospital beds density which reduced by $42 \%$ from 23 hospital beds per 10,000 people (MoH, 2013b) in 2013 to 13 beds per 10,000 people (Kenya Open Data) in 2016. There was no data available on health facilities with minimum equipment nor on availability of drugs post devolution. Therefore, no comparison could be made on these indicators.

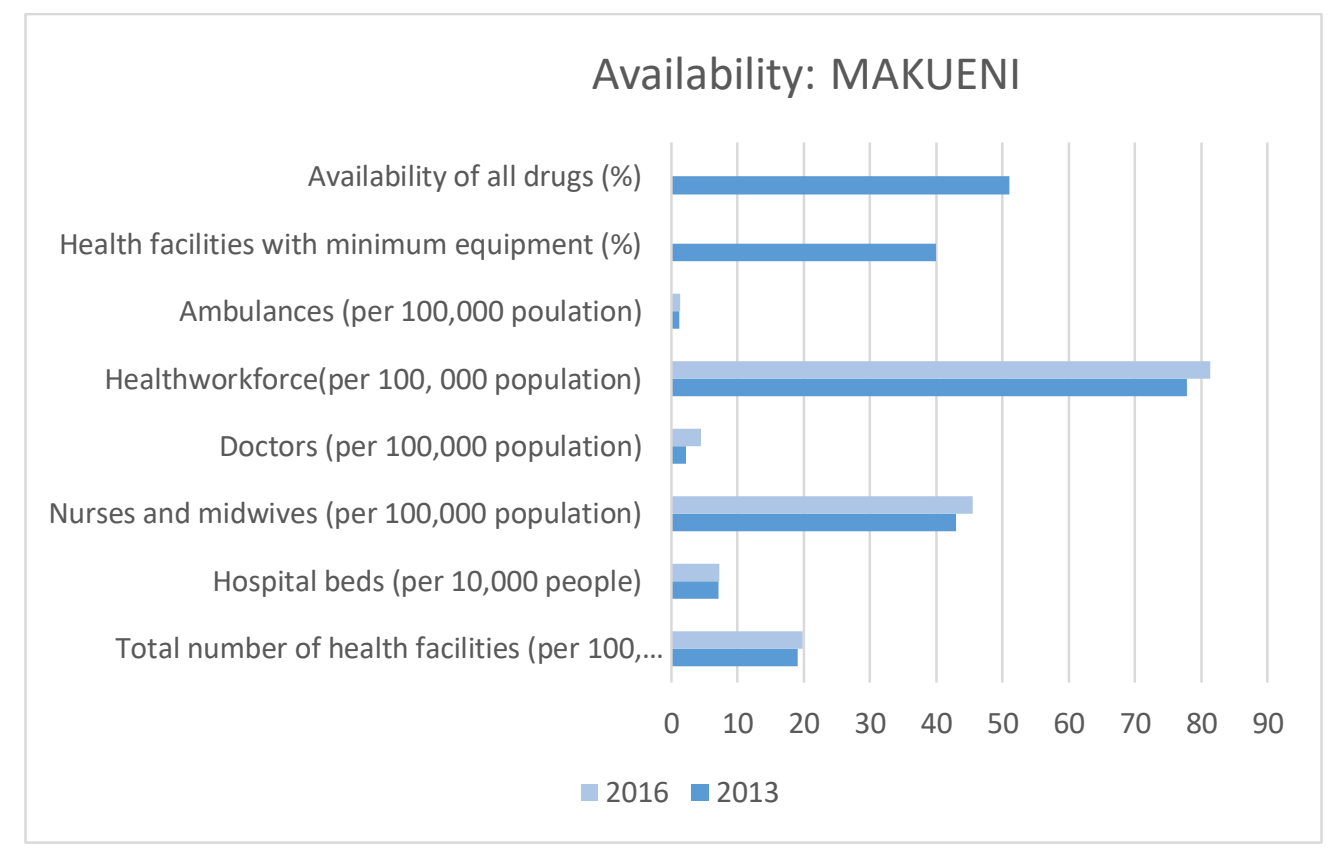

Figure 11: Availability of health services in Makueni County between 2013 and 2016

Source: MoH 2013b, 2016; HPP, 2013; KNBS, 2016; County Government of Makueni, 2016

Makueni county saw an overall increase in all availability indicators albeit smaller than Kisumu's. The number of health facilities increased by $4 \%$ post devolution while hospitals beds saw a small increase of $1 \%$ post devolution. The total health workforce increased by 
only 5\% from 77 workers per 100,000 population in 2013 (HPP, 2013) to 81 workers per 100,000 population in 2016 (KNBS, 2016). The number of doctors saw the biggest increment by $97 \%$ increasing from 2 doctors per 100,000 population in 2013 to 5 doctors per 100,000 population in 2016 . On the other hand, nurses only reported an increment of 6\% between 2013 and 2016. (MoH 2013b; KNBS, 2016). The number of ambulances increased by 12\% between 2013 and 2016. (MoH, 2013b; County Government of Makueni, 2016). There was no available data on health facilities with minimum equipment nor on availability of drugs after 2013 thus no trends could be established.

Of the two counties, Kisumu witnessed a significant increase in most indicators.

\subsection{Accessibility}

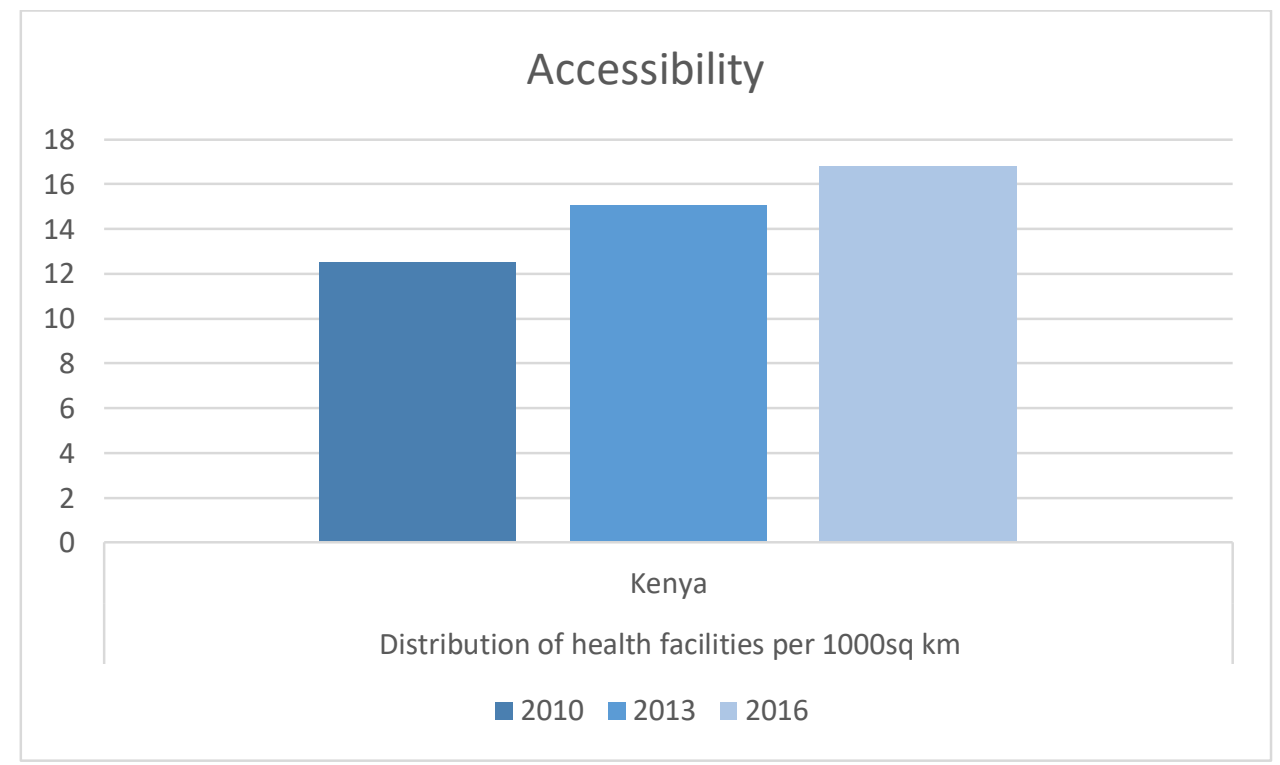

Figure 12: Accessibility of health services in Kenya between 2010 and 2016 Source: CRA, 2011; 2013;2016; MoH, 2013b; KNBS, 2016

Kenya's distribution of health facilities data shows an upward trend since 2010 with predevolution period witnessing a higher increase rate of $20 \%$ compared to post devolution's $12 \%$ increase rate (MoH 2013b; KNBS 2016). However, road network coverage has remained the same. Only $9.4 \%$ of the roads are paved. Since 2010 , the average distance to a health facility is constant at $4 \mathrm{~km}$. (CRA, 2011; 2013; 2016). 


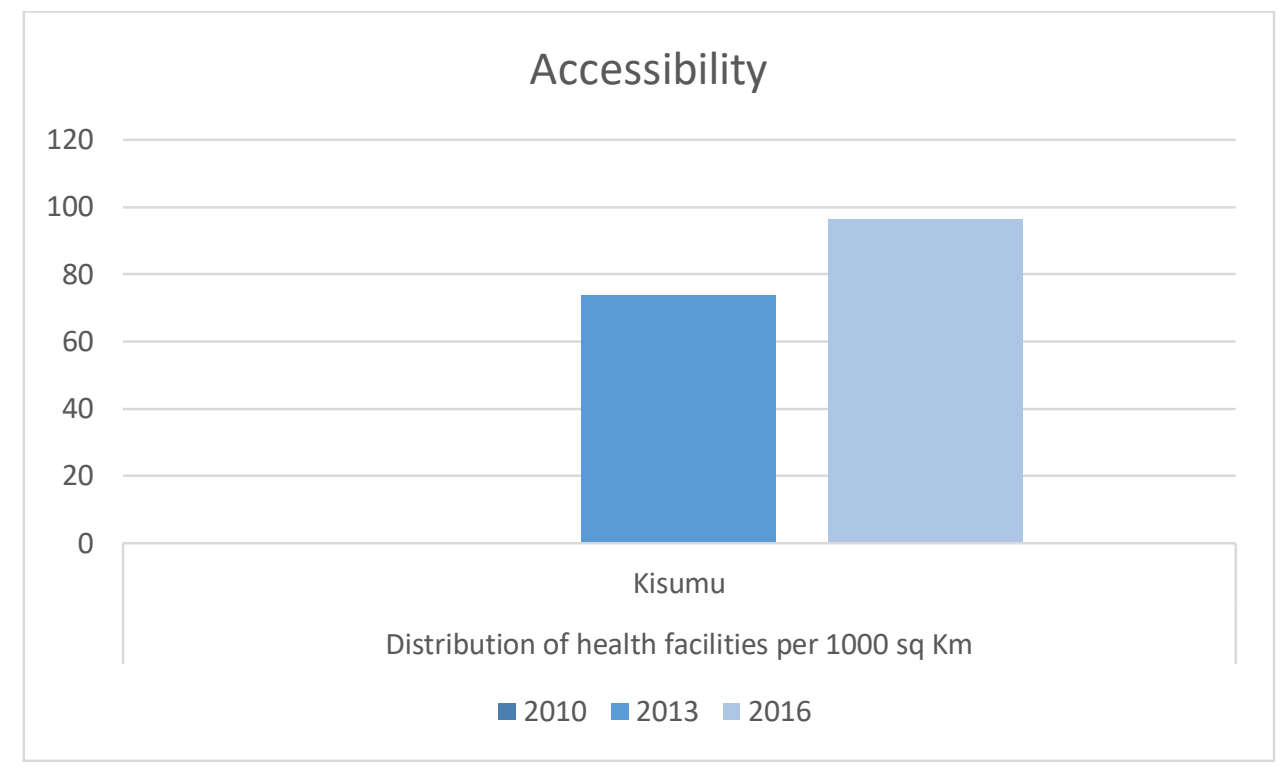

Figure 13: Accessibility of health services in Kisumu County between 2010 and 2016

Source: KNBS,2014; 2016

The data from Kisumu County showed a higher increase rate of distribution of health facilities at $31 \%$ compared to Kenya's post devolution rate at $12 \%$. Similar to Kenya's data, the percentage of paved roads has not changed since 2013 . It remains at $4.9 \%$ while the average distance to a health facility is $6.4 \mathrm{~km}$ (KNBS, 2014).

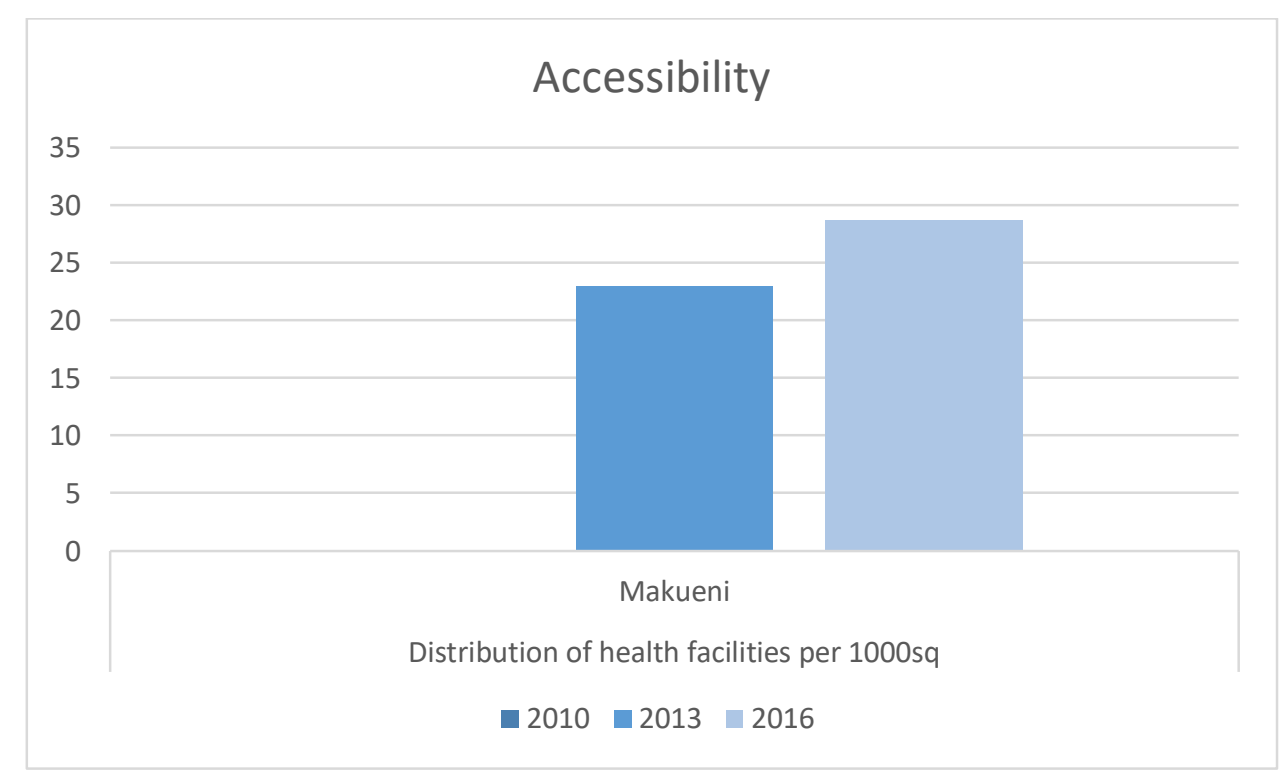

Figure 14: Accessibility of health Services in Makueni County between 2010 and 2016 Source: CRA, 2013; KNBS, 2014: 2016, County Government of Makueni, 2016

Makueni County's accessibility increased by 25\% from 22 facilities per 1000sq.km in 2013 (KNBS, 2014) to 28 facilities per1000sq.km in 2016 (KNBS, 2016). The percentage of paved 
roads in the county is still very low at $0.9 \%$ and hasn't changed since 2013 (CRA, 2013). The average distance to a health facility is still $6 \mathrm{~km}$ (County Government of Makueni, 2016).

\subsection{Affordability}

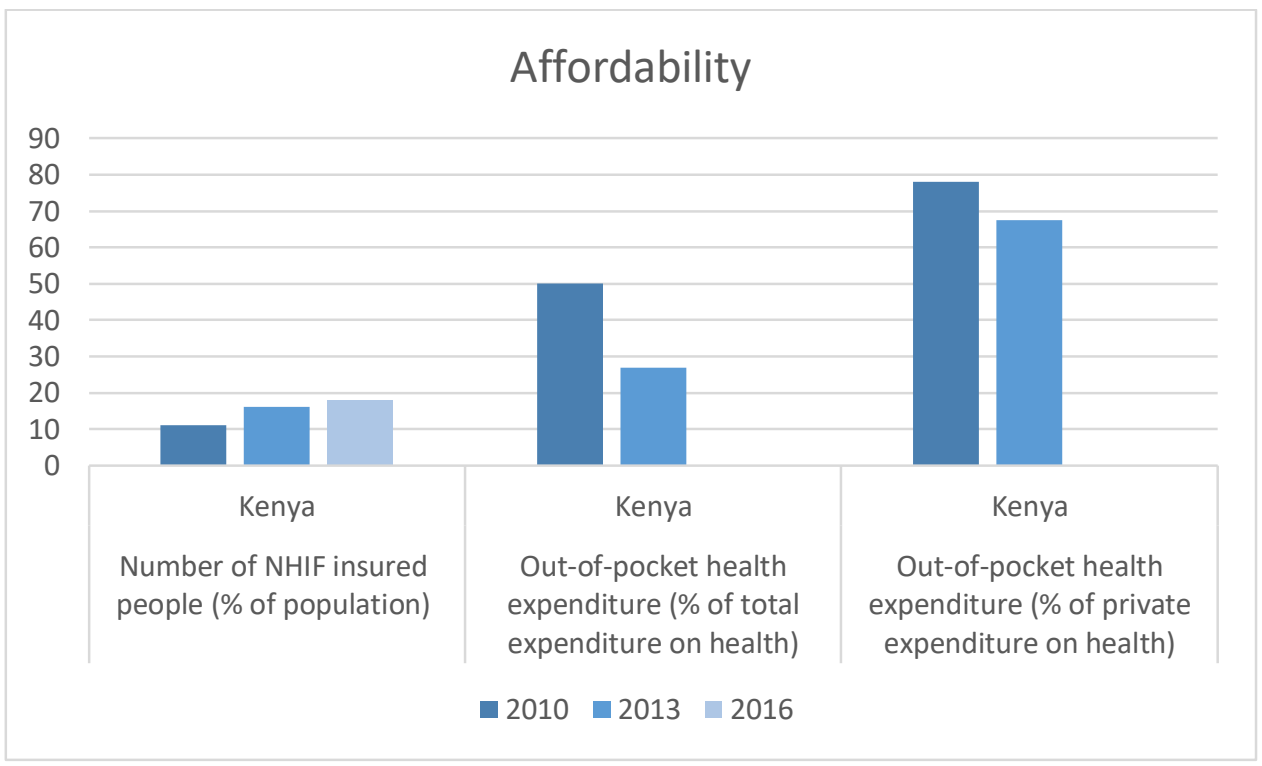

Figure 15: Affordability of health services in Kenya between 2010 and 2016

Source: MoH, 2015; worldbankdata.org

The data available showed that the percentage of NHIF insured people increased by $55 \%$ from $11 \%$ in 2010 to $17 \%$ in 2013 and stagnated afterwards to record a slow increase rate of only 5\% between 2013 and $2016(\mathrm{MoH}, 2015)$. The out of pocket health expenditure has reduced significantly. The share of OOP as a percentage of total health expenditure reduced from 50\%in 2010 (World Bank Data) to 26\% in 2013 (World Bank Data) and from78\% in 2010 to $67 \%$ in 2013 as a share of private health expenditure on health. 


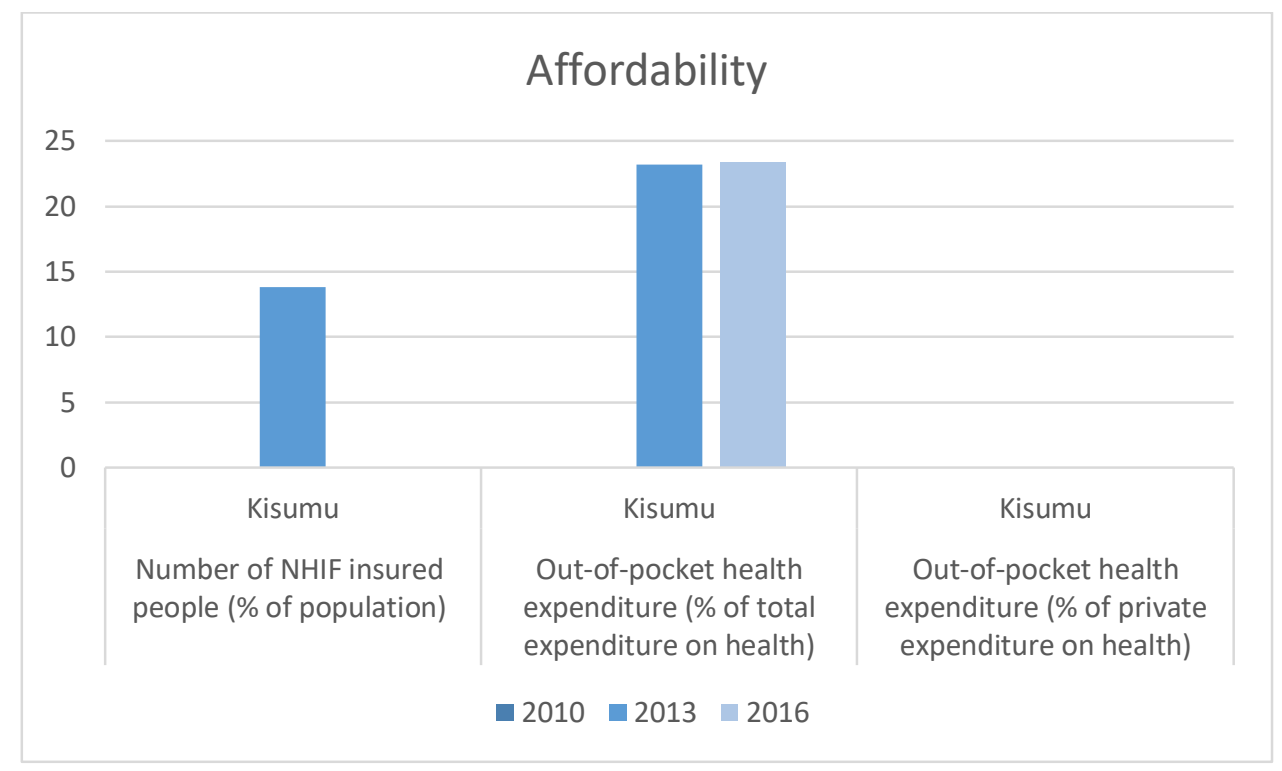

Figure 16: Affordability of health services in Kisumu County between 2010 and 2016

Source: KNBS, 2014; County Government of Kisumu, 2016a

Kisumu County's data was scarce on this indicator. The available data was extremely contradictory from different sources. The only data available on insurance coverage was of 2013 (KNBS, 2014) which showed only 13\% of the county's population was NHIF insured. The trend on out of pocket health expenditure was peculiar as it showed an increase whereas Kenya's average shows a decrease.

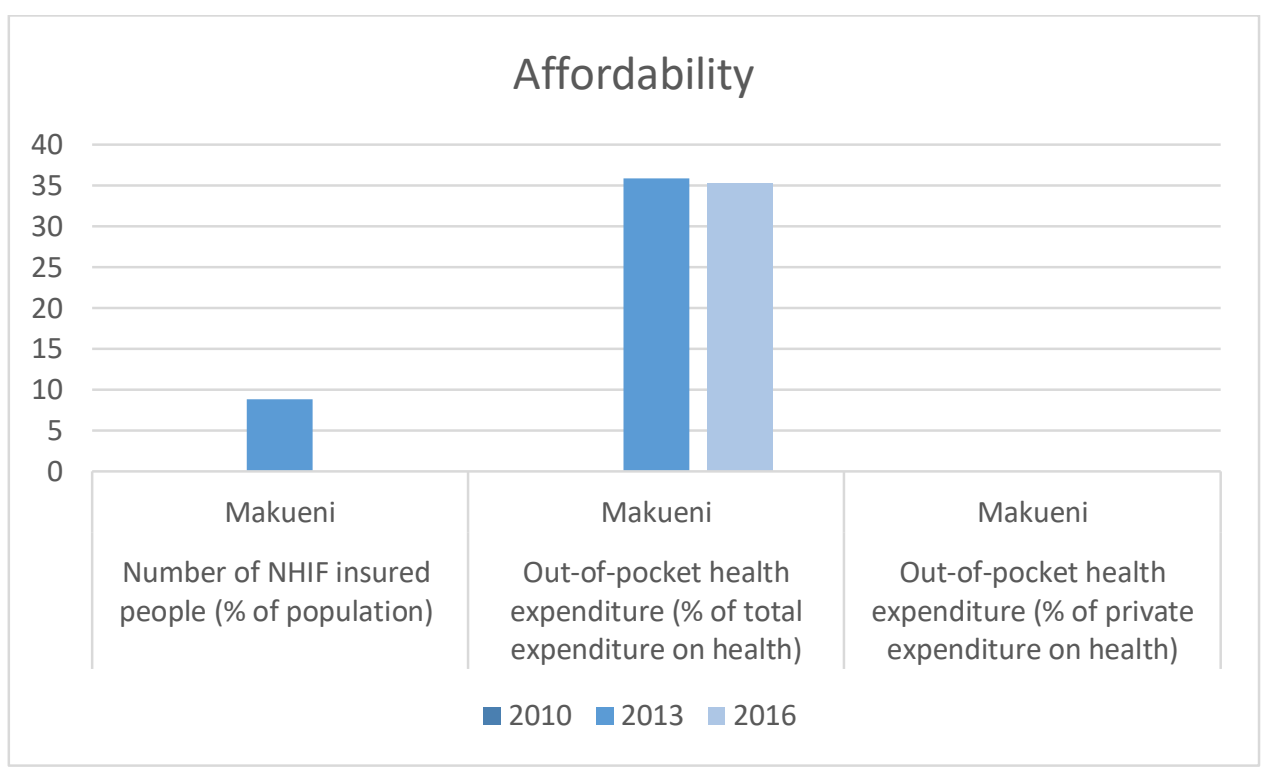

Figure 17: Affordability of health services in Makueni County between 2010 and 2016

Source: KNBS, 2014; County Government of Makueni, 2013;2016

Like Kisumu, Makueni's data on health insurance coverage was scarce. However, the 2013 data showed that only $8 \%$ of the population was covered by NHIF which is way below the 
country's $17.1 \%$ at the time (KNBS, 2014). The out of pocket health expenditure however showed a decrease of 2\% from 2013-2016 (County Government of Makueni 2013; 2016).

In summary, Kenya's national data shows an increase in all access to health care indicators. County data however is inconclusive. Kisumu gives mixed results while Makueni shows an increase in all indicators. The following chapter discusses and analyses the above data to generate conclusions. 


\section{Discussion and Conclusion}

This chapter seeks to interpret the findings of the data using the conceptual framework identified in the literature review. It will attempt to draw conclusions that can contribute to the debate about health decentralization.

\subsection{Discussion}

Kenya's data shows a general increase in access to health care services since 2010. However, the increase rate in health facilities density before devolution is bigger at $6 \%$ compared to post devolution's $1 \%$. This suggests that counties did not build more health facilities at the same pace as national government. On the other hand, the health workforce increase rate was bigger in post devolution period at $42 \%$ compared to before devolution at 7\%. This can be explained by the big recruitment of health workers by county governments from 2013 onwards.

Kisumu and Makueni counties have shown a positive impact of devolution on access to healthcare. This can be explained by the commitment of both to spend more on health. The national target of county government's health expenditure as a percentage of total county government expenditure is $20 \%$. Both counties have surpassed this since 2013. Kisumu stands at $27 \%$ while Makueni stands at 26\% (HPP, 2016).

In comparing the two cases, Makueni saw an increase in all indicators of access to health care. This is primarily a result of the heavy investment by the county government. Makueni is one of the counties reported to have the highest allocation of its total budget to its health department in the country. In 2013 , it allocated $48 \%$ of its total budget to health which has since increased to $51 \%$ (ibid). In comparison, Kisumu allocated $37 \%$ of its budget to the health department in 2013 and slightly increased it to 38\% in 2016 (ibid). It is important to note though that Kisumu gets additional funding from donors who support HIV/AIDS programs in the county. While Kisumu currently gets $23 \%$ of its health funding from donors, Makueni only gets $8 \%$ (ibid). This explains the disparity in the increase rates of availability indicators and suggests that if there was no additional donor funding, Kisumu and Makueni would have rough equivalence of the impact of devolution on access to healthcare services. 
In general, Kisumu represented the case of the greatest impact of devolution on availability of healthcare services. The sudden increase of health workforce by 274 percent compared to Makueni's five percent is an indication that Kisumu spent more on hiring additional workforce. Indeed, the county annual financial year 2015/2016 shows two thirds of Kisumu's health budget was spent on recurrent expenditure. See Figure 18 below.

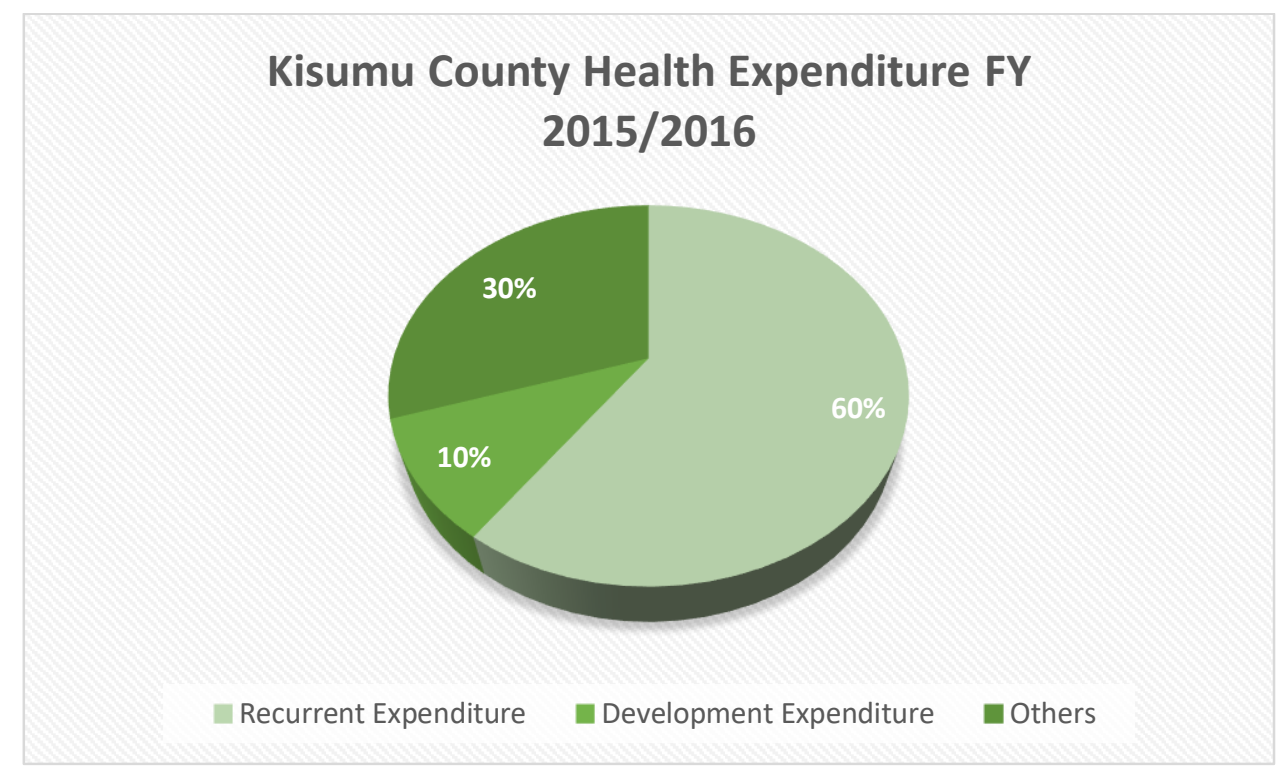

Figure 18: Kisumu's health expenditure summary for FY 2015/2016

Source: County Government of Kisumu, 2015b

However, looking at the breakdown of the workforce (Kenya open data), Kisumu employed lower cadre workforce particularly casual staff more than the needed doctors and nurses. This represents a mismatch of skill mix compared to the county's health needs. On the other hand, Makueni's 5\% increase of total health workforce represented a good skill mix of all cadres (KNBS, 2016). However, this increase is so low compared to the national's $42 \%$ increase between 2013 and 2016. This might be because of underreporting by Makueni county health department as the increase rate of doctors at $97 \%$ was as high as Kisumu's 199\% increase rate compared to Kenya's 16\% increase rate between 2013 and 2016.

There was a significant distinction between the two counties in the total density of hospital beds. The decrease of total density of hospital beds in Kisumu from 23 beds per 10,000 population in 2013 to 13 beds per 10,000 population in 2016 could be explained by the county government's huge expenditure on personal emolument as seen in figure 18. In addition, the failure of Kisumu County Government to increase the number of beds 
concurrently with the rising population explains the decrease in hospital beds density. Furthermore, Kisumu built more primary health care facilities (County Government of Kisumu, 2015a) which typically do not offer inpatient services.

Still, the county was able to increase the number of health facilities. Although this is the case, it is important to note that a significant share of this increase was in health dispensaries and not hospitals (KNBS, 2017). Scholars (Gupta et al, 2015) argue that politicians are more likely to invest in projects that take less resources and time for visibility purposes. Indeed, the timing of the launch of these projects during the peak of election campaigns is suspect. Governors, who are county managers, are elected and thus would hurriedly launch projects for political mileage. This leads to the question of quality. A number of ambulances bought by county governments for instance were found out to be non-functional (Daily Nation, 2014). In as much as there was the increase of health services, quality became an issue.

The lack of increase of secondary health facilities can also be explained by the dispute around county hospitals responsibility (County Government of Kisumu, 2016a). Kisumu has a secondary health facility, Kisumu County Hospital which before devolution used to cater for populations outside the district. However, the distinctiveness of counties now brings the question of catering for this population from neighbouring Homabay and Siaya Counties. While the hospital can't send away the patients, the county gets more burdened by the increasing demand of health services. This is in addition to its decision to inject resources to the national referral hospital, Jaramogi Oginga Odinga, which is located in the county (County Government of Kisumu, 2015b) despite getting additional allocation of resources from national government for the level 5 hospital (County Allocation of Revenue Act, 2015). According the Constitution (2010) this should not be the case as national referral hospitals are under the national government which provide conditional grants to the hospitals. This diversion of money could explain why the county and sub-county health facilities do not have sufficient infrastructure $(\mathrm{MoH}, 2013 \mathrm{~b})$.

Makueni on the other hand has spent fewer resources in building health facilities and more in equipping the existing ones. Makueni's budget is slightly balanced between the recurrent and development expenditure (County Government of Makueni, 2016 b). See figure 19 below. 


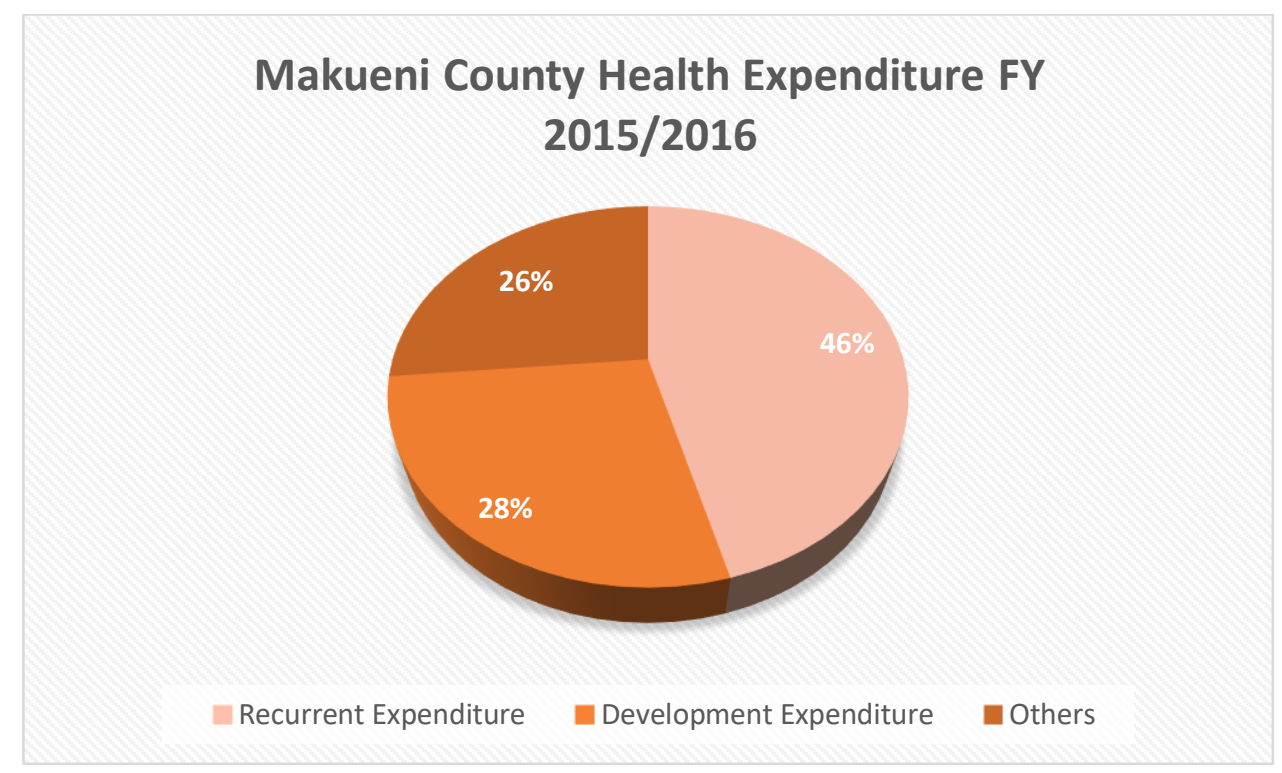

Figure 19: Makueni's health expenditure summary for the FY 2015/2016

This explains the increase in hospital beds density between 2013 and 2015. However, accessibility to these health facilities remains a big challenge. The national average distance to a health facility target is $4 \mathrm{Km}$. The population in Makueni spend more time and costs to reach a health facility at an average distance of $6 \mathrm{~km}$. In addition, the poor road network coverage in the county exacerbates this situation. The situation is similar in Kisumu County where the average distance is $6.4 \mathrm{Km}$. The data on this was however not conclusive as no document captured the percentage change of paved roads length. The counties' budget (2015) do not give a breakdown of the development expenditure per sector and thus it was not possible to determine what percentage of the total county government expenditure was allocated to transport. Both counties acknowledge that indeed road network affects physical accessibility of health facilities. However, they argue that roads construction and maintenance is under the national government (County Government of Makueni, 2015b). Unsurprisingly, in their annual development plans, there are possible political hints to the national government to allocate resources to road construction equitably (ibid).

This is in contrast to the Constitution's (2010) stipulation of transport as a function of the county government. Yet, Makueni (County Government of Makueni, 2016) argues that it is situated along the main route that connects the capital to the coastal towns and as such depend on government's investment in Nairobi-Mombasa highway and the Standard Gauge Railway to increase physical accessibility. Whilst nothing has been reported on road network 
coverage, the two counties have managed to increase distribution of health facilities post devolution by $31 \%$ in Kisumu and 25\% in Makueni against Kenya's 12\%.

The distribution of health facilities both per unit of population and per sq.km data presents an interesting picture. The health facilities per unit of population in Makueni County is more than in Kisumu County yet they have almost similar population total. This implies that Makueni County's health facilities are more equitably distributed albeit it's highly dispersed population. On the distribution of health facilities per sq.km, Kisumu has more facilities compared to Makueni. This suggests that Kisumu's facilities are distributed more equitably in all sub-counties. Except, Kisumu does not take its highly dense population into account. For example, Kisumu Central sub-county has 5165 people per sq.km while Muhoroni subcounty has 218 people per sq.km (County Government of Kisumu, 2016a) yet they are served by a similar number of health facilities. Therefore, having the same number of facilities serving these two sub-counties only increases inequity of access to healthcare services within the county reinforcing the argument that decentralization increases health inequities (Collins \& Green, 1994) and inefficient distribution of health facilities (Gravelle, 2003).

Inconsistent with the other indicators, affordability has mixed results among users of health care in the two counties. In Kisumu, the Out of Pocket (OOP) health expenditure as a share of total expenditure on health has increased post devolution which contrasts the national decreasing trend. This could be explained by the new rise of HIV infections in the county $(\mathrm{MoH}, 2016)$. It could also be argued that the OOP health expenditure as a share of total expenditure has increased as the county government seeks to increase user fees to finance their services as Mitchell and Bossert (2010) contend. Yet, this is not the case as the MoH abolished all user fees at primary level and compensate county governments through conditional grants (The County Revenue Allocation Act, 2015). Therefore, the heavy HIV/AIDS burden explains this inconsistency.

In addition, as poverty is high in the County, only $13 \%$ of the population was reported to be insured in 2013. This denotes a lot of people have to pay costly for healthcare. Yet this is not the case. The County's OOP health expenditure at $23 \%$ of the private health expenditure is lower than the national's $26 \%$. This is because the number of not for profit health facilities offering cheaper services is quite high in the county. 
While Makueni suffers similar rates of poverty as Kisumu and an even less coverage of insured population at $8 \%$ of the total population, the OOP health expenditure as a share of the total health expenditure reduced. This is due to the county government's commitment to provide free health care for all. In fact, the County governor unveiled an ambitious insurance plan for its population to get free health care (Daily Nation, 2016). Still, the county's OOP health expenditure is above Kenya's $26 \%$ indicating that the healthcare services in the county are expensive. Although, it is important to note that Makueni has a higher number of private health facilities that have costly services compared to Kisumu.

The detailed analysis of the effects of devolution on availability, accessibility and affordability of healthcare services in the two counties provides a general assessment of the effects of devolution on access to healthcare services in Kenya. First, there was an overall increase in the availability of health workforce, facilities and equipment in both counties. However, Kisumu had a decrease in the total density of hospital beds. More so, devolution has not changed the physical accessibility of health facilities in both counties but has increased distribution of health facilities. However, this increase has resulted in access inequities within Kisumu County. Finally, findings on devolution's effects on affordability in the two counties show mixed results.

This analysis adds to the debate on impact of devolution on health provision. In the following section, this research attempts to generalize these findings to the wider literature.

\subsection{Comparing the findings to the literature}

\subsubsection{Availability}

The results of this research imply that devolution has increased availability of healthcare services in Kenya. Using a panel data of 21 provinces from 1980-1993, Yee (2001) finds that in China, fiscal decentralization resulted in an increase in the number of doctors per 10,000 population but was inconclusive on its impact on density of hospital beds. However, other studies show a negative correlation. Sharma and Mwonge (2010) report a shortage of staff and drugs stock out in Nepal during the decentralization period. This is because Nepal local governments lacked allocation powers and thus had to spend money per the Central Government's spelt out functions and not local needs. Bossert and Beauvais (2002) also report inadequate availability of drugs in the Philippines post decentralization. 
Lakshminrayanan (2003) confirms this through his study that finds out there was chronic lack of equipment and availability of drugs as well as a disruption of referral system in the Philippines. Likewise, Campos-Outcalt et al (1995) in their qualitative study carried out in Papua New Guinea find that no new equipment was purchased by district offices as money for health sector was being diverted to other use. But they clarify that at the same time, there was a remarkable decrease of national health expenditures in 1989 and in 1991 during the decentralization period (ibid). Utilizing both quantitative and qualitative data, Kristiansen and Santoso (2006) as well state that users in Indonesia complained that there were no medical workers and drugs in public hospitals. This is because the government reduced public funding on health in an attempt to transfer its public services responsibility to lower level units.

Most of these findings show a negative correlation particularly in availability of drugs and health workforce. In contrast, this study finds that Kenya's health workforce increased post devolution suggesting that devolution improved availability of healthcare services. It can be argued that Kenya improves because the county governments have the power to allocate resources and plan their budgets without the interference of the national governments. As such, county governments have allocated almost $70 \%$ of their total budget to recurrent expenditure (County Revenue Allocation Act, 2015). This explains the increase of health workforce contradicting the effects of decentralization on availability of health workforce in other countries.

As this study did not find quantitative data on availability of drugs in Kenya's counties post 2013, no conclusion could be drawn on this indicator. Although, this research assumes that as all other indicators showed an increase, the percentage of available drugs most likely increased.

\subsubsection{Accessibility}

This study findings show mixed results on access to health facilities. Devolution cannot be said to have affected road network coverage in Kisumu and Makueni Counties nor reduced their average distance to a health facility although it has increased the distribution of health facilities. In contrast, one study (Regmi et al., 2009) finds that decentralization in Nepal increased access to services. 
Yet, in his statistical analysis, Bustamante (2010) finds that in Mexico, areas which were centralized had better access to hospital services as compared to areas that were decentralized because centralised areas received government funding. In Bangladesh, poor access to health facilities and poor infrastructure led to unwillingness by health workers to work in the local governments (Ahmad et al., 2007). Similarly, Simatupang (2009) reports that poor access to facilities led to decline of performance of health services in Indonesia.

While most studies find negative impact of decentralization on accessibility of health facilities due to poor infrastructure, this study is inconclusive on this measure due to lack of substantive data. However, it is safe to argue that devolution was expected to increase county infrastructure especially rural road network. But both counties budget analysis show that road and construction works receive limited allocation of resources.

\subsubsection{Affordability}

The reduction of health costs depends on the government's willingness to spend on health. Faguet (2004) in his study finds that Bolivia increased local spending on health needs which improved health outcomes in the country. Similarly, this study finds that the increase in Makueni county government spending on health has reduced the OOP health expenditures by $2 \%$ between 2013 and 2016 .

However, Kisumu County shows an increase in the OOP health expenditure indicating a negative effect of devolution. Equivalently, Kristiansen and Santoso (2006) find that the costs of health services in Indonesia were higher post decentralization. Bustamante (2010) also finds that the costs of health services in Mexico were higher in decentralised states compared to centralised states due to government subsidies to the centralised states. The results on this indicator are generally inconclusive.

\subsection{Conclusion}

This research attempted to fill the gap in the current literature on the impact of decentralization on provision of healthcare services using the unique case of Kenya. The study adopted a case-study approach going against the norm of purely quantitative and qualitative studies in the discourse. The data collected was mainly secondary quantitative from a number of government institutions and international development agencies. It also 
used existing literature to explain the ramifications of the findings on health decentralization debate. The overall question was whether devolution has improved provision of healthcare services in Kenya.

Devolution has generally improved provision of healthcare services. The availability of health care services has increased since 2013. However, devolution has not had an effect on accessibility. The results on affordability are mixed. Overall, it can be argued that it has improved provision of healthcare services even though other external factors have affected this for example donor funding. Nonetheless, the commitment by county governments to spend more on health cannot be denied. As seen from other studies' findings, devolution can only work when the government is willing to give the local governments powers to allocate resources per their needs which is the case in Kenya.

Apart from improving allocation of resources according to the local needs, devolution tackles marginalization problems. If well implemented, this could reduce inequities not only within the country but within the counties. However, devolution also experiences challenges. A major challenge is the quality of services being provided. There is a danger of providing low quality services in an effort to save money. Therefore, for purchasing of health equipment such as ambulances, counties should coordinate and purchase from one supplier. This not only increases their bargaining power, but ensures quality and equal standards across the counties.

Another challenge is the human resource. It is understandable that recurrent expenditure takes up a huge percentage of the local government expenditure because of hiring needs. However, counties should ensure there's a match of mixed skills to the local health needs. In addition, the national government should ensure timely release of funds (as clearly most of it goes towards salaries) to avert future health workforce strikes. As more counties are spending their development expenditure on building and rehabilitating existing facilities, other health inputs such as commodities and equipment should not be forgotten. Furthermore, county governments should cooperate on the principle of intergovernmental relations when it comes to shared resources such as county hospitals which serve populations from outside their counties. Using the same principle, the counties should cooperate with the national government in areas such as transport which is clearly an external factor that affects accessibility of health facilities. 
Devolution has greater opportunities for the health sector in Kenya. With the full support of the central ministry, constitution, public and allocation of resources, it has the potential of improving provision of health services in the country even further.

This far, this research acknowledges its limitations. Firstly, because of data limitations, it was not possible to identify trends in all indicators making it difficult to answer the overall question. Therefore, it does not claim this as the picture of the whole country but gives an indication of the impact of devolution on access to health services. It was also impossible to identify pre- and post devolution trends for counties as the researcher could not get data on the former districts before 2013. As such, research made conclusions from comparison drawn on post devolution period between the two counties, Kenya and other countries. This is as far as the available data could be analysed.

To this end, this study would like to outline two issues that arose from the data analysis. Firstly, the unbalanced county budgets threaten the development of counties. Yet, counties cannot afford to reduce salaries or fire workers as county governments' leadership is political. This presents a ticking time bomb. The other issue is on the quality of health care services provided by the counties as there's no clear accountability mechanisms. Future research should thus pay attention to these within the Kenyan context to overcome the challenges of health care decentralization. 


\section{References}

Aday, L.A. and Andersen, R., 1974. A framework for the study of access to medical care. Health services research, 9(3), p.208.

Agoro, O.O., Osuga, B.O. and Adoyo, M., 2015. Supportive supervision for medicines management in government health facilities in Kiambu County, Kenya: a health workers' perspective. Pan African Medical Journal, 20(1).

Ahmad, J.K., Devarajan, S., Khemani, S. and Shah, S., 2005. Decentralization and service delivery. World Bank Policy Research Working Paper 3603

Ahmad, A., Bose, M. and Persson, T.H., 2007. Decentralized provision of primary healthcare in rural Bangladesh-A study of government facilities. In The annual conference of the Norwegian association for development research on making institutions work for the poor, Bergen (pp. 5-7).

Anderson, D.M., 2005. "Yours in Struggle for Majimbo". Nationalism and the Party Politics of Decolonization in Kenya, 1955-64, Journal of Contemporary History 40, 3: 547-64.

Andrews, M. and Schroeder, L., 2003. Sectoral decentralisation and intergovernmental arrangements in Africa. Public Administration and Development, 23(1), pp.29-40.

Asia Development Bank \& World Bank, 2005. Decentralization in the Philippines: Strengthening local government financing and resource management in the short term. Joint Document of World Bank and Asian Development Bank Manila, Philippines

Atkinson, S. and Haran, D., 2004. Back to basics: does decentralization improve health system performance? Evidence from Ceará in northeast Brazil. Bulletin of the World Health Organization, 82(11), pp.822-827.

Barasa EW, Manyara AM, Molyneux S, Tsofa B, 2017. Recentralization within decentralization: County hospital autonomy under devolution in Kenya. PLOS ONE 12(8): e0182440.

Barker, C., A. Mulaki, D. Mwai, and A. Dutta., 2014. Devolution of Healthcare in Kenya: Assessing County Health System Readiness in Kenya: A Review of Selected Health Inputs. Washington, DC: Futures Group, Health Policy Project

Berman, P. (1995) Health sector reform: making health development sustainable. In Health Sector Reform in Developing Countries: Making Health Development Sustainable, ed. P. Berman, pp. 13-36. Harvard School of Public Health, Boston.

Besley, T., Coate, S., 2003. Centralized versus decentralized provision of local public goods: a political economy analysis. Journal of Public Economics 87 (12), 2611-2637

Boone, C. 2003. Decentralization as political strategy in West Africa, Comparative Political Studies 36: 355-80 
Bossert, T., 1998. Analyzing the decentralization of health systems in developing countries: decision space, innovation and performance. Social science \& medicine, 47(10), pp.1513-1527.

Bossert T. (2000) Decentralization of health systems in Latin America: a comparative study of Chile, Colombia, and Bolivia. Boston (MA): Harvard School of Public Health.

Bossert T, Beauvais, J. 2002. Decentralization of health systems in Ghana, Zambia, Uganda and the Philippines: a comparative analysis of decision space. Health Policy and Planning pp. 17:14-31.

Bossert, T.J., Larranaga, O., Giedion, U., Arbelaez, J.J. and Bowser, D.M., 2003.

Decentralization and equity of resource allocation: evidence from Colombia and Chile. Bulletin of the World Health organization, 81(2), pp.95-100.

Burki, S.J., Guillermo P., and Dillinger. W., 1999. Beyond the Center: Decentralizing the State. World Bank: Washington, D.C.

Burns, D., Hambleton, R and Hoggett, P., 1994. The Politics of Decentralisation: Revitalising Local Democracy; Macmillan, Basingstoke.

Burugu, J.N., 2010. The county: understanding devolution and governance in Kenya.

Bustamante, A.V., 2010. The trade-off between centralized and decentralized health services: evidence from rural areas in Mexico. Social science \& medicine, 71(5), pp.925-934.

Campos-Outcalt et al., 1995. Decentralization of health services in Western Highlands Province, Papua New Guinea: an attempt to administer health service at the subdistrict level. Social Science and Medicine 40(8), 1091-1098.

Cheeseman, N., Lynch, G. and Willis, J., 2016. Decentralisation in Kenya: the governance of governors. The Journal of Modern African Studies, 54(1), pp.1-35.

Chen, A., Dutta, A. and Maina, T., 2014. Assessing the Quality of Primary Healthcare Services in Kenya. Health Policy Project, Futures Group

Çınar, F., Eren, E. and Mendeş, H., 2013. Decentralization in health services and its impacts: SWOT Analysis of Current Applications in Turkey. Procedia-Social and Behavioral Sciences, 99, pp.711-718.

Commission on Revenue Allocation. 2011. Kenya County Fact Sheets. First Edition

Commission on Revenue Allocation. 2013. Kenya County Fact Sheets. Second Edition.

Conyers, D., 1983. Decentralization: The latest fashion in development administration? Public Administration and Development, 3(2), pp.97-109.

Conyers, D., 1984. Decentralization and development: A review of the literature. Public Administration and Development, 4(2), pp.187-197. 
Conyers, D., 2007. Decentralisation and Service Delivery: Lessons from Sub-Saharan Africa. IDS bulletin, 38(1), pp.18-32.

County Allocation of Revenue Bill, 2015. Government of Kenya. Nairobi, Kenya.

County Government of Kisumu. 2013. Kisumu County Integrated Development Plan, 20132017

County Government of Kisumu. 2015a. Annual Development Plan FY 2015/2016

County Government of Kisumu. 2015c 2013/14 and 2014/15 County Health Accounts.

County Government of Kisumu 2015d. Fiscal Strategy Paper for FY 2015/2016

County Government of Kisumu. 2016a. Annual Development Plan FY 2016/2017

County Government of Kisumu. 2016b Budget Estimates Fiscal Year 2016/2017

County Government of Makueni. 2013. Makueni County Integrated Plan, 2013-2017.

County Government of Makueni. 2015a. 2013/14 and 2014/15 County Health Accounts. Nairobi: Government of Kenya.

County Government of Makueni. 2015b. Annual Development Plan FY 2015/2016

County Government of Makueni. 2015c. Fiscal Strategy Paper for FY 2015/2016

County Government of Makueni. 2016. Annual Development Plan FY 2016/2017

Daily Nation. (2013). Govt rolls out free maternal care. [Online] Available at:

http://www.nation.co.ke/news/Govt-rolls-out-free-maternal-care/1056-1869284 -

11xiis8z/index.html [Accessed Aug. 2017].

Daily Nation. (2014). Scandal of imported 'converted' ambulances. [online] Available at: http://www.nation.co.ke/news/Ambulances-County-Governments-Conversions/10562452092-10cn6n1/index.html [Accessed Aug. 2017] .

Daily Nation. (2016). Makueni launches ambitious 'free healthcare' plan. [online] Available at: http://www.nation.co.ke/counties/Makueni/Makueni-County-to-offer-freehealthcare-to-residents/1183294-3383768-ajy6ly/index.html [Accessed Aug. 2017].

Dale, A., Arber, S. and Procter, M., 1988. Doing secondary analysis. Unwin Hyman.

Data.worldbank.org. (n.d.). Kenya / Data. [Online] Available at:

https://data.worldbank.org/country/kenya.

Denscombe, M., 2014. The good research guide: for small-scale social research projects. McGraw-Hill Education (UK).

De Vaus, D.A. and de Vaus, D., 2001. Research design in social research. Sage.

Diop, M., Gaye, D., Giugale, M., Fajnzylbe, P. and Kiringai, J. (2014). Laying The Foundation For A Robust Health Care System In Kenya: Kenya Public Expenditure Review. [ebook] World Bank, p.40. Available at: 
http://documents.worldbank.org/curated/en/278451468038960033/pdf/940210WP Ov20Bo0-Vol01120140FINALpdf.pdf.

Donabedian A.1972. Models for organising the delivery of personal health services and criteria for evaluating them. Milbank Memorial Fund Quarterly: 103-154

Dopson, S., 2003. The potential of the case study method for organisational analysis. Policy \& Politics, 31(2), pp.217-226.

Exworthy, M., 1994. The contest for control in community health services: general managers and professionals dispute decentralisation. Policy \& Politics, 22(1), pp.17-29.

Faguet, J. 2004. Does Decentralization Increase Responsiveness to Local Needs? Evidence from Bolivia. Policy Research Working Paper No. 2516, The World Bank, Washington, D.C.

Flick, U., 2011. Mixing methods, triangulation, and integrated research. Qualitative inquiry and global crises, 132.

Freeborn, D.K. and Greenlick, M.R., 1973. Evaluation of the performance of ambulatory care systems: Research requirements and opportunities. Medical Care, 11(2), pp.68-75.

Gathura, G. 2015. Revealed: Why quality of health care is declining. [Online] The Standard. Available at: https://www.standardmedia.co.ke/article/2000161086/revealed-whyquality-of-health-care-is-declining.

Ghuman, B.S. and Singh, R., 2013. Decentralization and delivery of public services in Asia. Policy and Society, 32(1), pp.7-21.

Government of the Republic of Kenya. 2007. Kenya Vision 2030: A Globally Competitive and Prosperous Kenya. Nairobi: Ministry of Planning and Development http://education.nairobiunesco.org/PDFs/Kenya VISION\%202030-final\%20reportOctober\%202007.pdf

Government of Kenya. 2010. Kenya Health Situation Analysis, Trends and Distribution, 1994 - 2010 and Projections to 2030. Ministry of Medical Services, Ministry of Public Health, and Sanitation.

Gravelle H (2003): "A comment on Weale's paper from an economic perspective", in: Equity in health and health care, proceedings from a meeting of the health equity network, The Nuffield Trust, London.

Gulliford, M., Figueroa-Munoz, J., Morgan, M., Hughes, D., Gibson, B., Beech, R. and Hudson, M., 2002. What does' access to health care' mean? Journal of health services research \& policy, 7(3), pp.186-188.

Gupta, Sanjeev, Estelle Liu, and Carlos Mulas-Granados, 2015, Now or Later? The Political Economy of Public Investment in Democracies," IMF Working Paper 15/175 (Washington: International Monetary Fund).

Gulzar, L., 1999. Access to health care. Journal of nursing scholarship, 31(1), pp.13-19. 
Health Care Access. 2002. Mcgraw-Hill Concise Dictionary of Modern Medicine. Retrieved August 12017 from http://medicaldictionary.thefreedictionary.com/health+care+access

HPP. 2013. Kenya County Health Fact Sheets. [Online] Available at: https://www.healthpolicyproject.com/index.cfm?id=kenyaCHFS.

HPP. 2016. Kenya County Health Accounts. Summary of Findings from 12 Pilot Counties Homedes, N. and Ugalde, A., 2005. Why neoliberal health reforms have failed in Latin America. Health policy, 71(1), pp.83-96.

Institute of Medicine (IOM) 1993. Committee on Monitoring Access to Personal Health Care Services. Access to health care in America. Washington, DC: National Academy Press.

Kenya Healthcare Sector: Opportunities for the Dutch Life Sciences \& Health Sector. 2016. [pdf] Nairobi: The Embassy of the Kingdom of Netherlands in Nairobi, pp.19-37. Available at:

https://www.rvo.nl/sites/default/files/2016/10/2016_Kenyan_Healthcare_Sector_R eport_Compleet.pdf [Accessed 27 Jul. 2017].

Kenya's Health Policy Framework, 1994. Nairobi, Kenya: Government Printers, Ministry of Health.

Kenya Health Policy 2012 - 2030. Ministry of Medical Services, Ministry of Public Health, and Sanitation.

Kenya Open Data, 2016. Opendata.go.ke. (2016). County Data. [Online] Available at: http://www.opendata.go.ke/datasets?bbox=33.981326\%2C0.102004\%2C35.185326\%2C1.101997\&q=Kisumu [Accessed Jul. 2017].

KIPPRA and HPP. 2014. Public Expenditure Tracking Survey, 2012 (PETS-Plus). Washington, DC: Futures

KNBS and ICF Macro. 2010. Kenya Demographic and Health Survey 2008-09. Calverton, Maryland: KNBS and ICF Macro.Group, Health Policy Project.

KNBS and ICF Macro. 2014. Kenya Demographic and Health Survey 2013-14. Calverton, Maryland: KNBS and ICF Macro. Group, Health Policy Project.

KNBS. 2017. Economic Survey 2017. Nairobi

KNBS. 2016. Statistical Abstract 2016. Nairobi

KNBS. 2014. Economic Survey 2013. Nairobi

KNBS. 2011. Economic Survey 2010. Nairobi

Khaleghian, P. 2004. Decentralization and public services: the case of immunization. Social Science \& Medicine 59(1):163-183. 
Kibua, T.N. and Mwabu, G.M. eds., 2008. Decentralization and devolution in Kenya: New approaches. University of Nairobi Press.

Kilonzo, S., Kamaara, E. and Magak, K., 2017. Improving Access to Maternal Health Care through Devolution in Western Kenya. IDS Bulletin, 48(2).

Kipruto, A.K. and Letting, N., 2017. Factors Influencing Provision of Health Care in a Devolved System of Government, Bungoma County, Kenya. Global Journal of Health Sciences, 2(1), pp.13-38.

KPMG Africa. 2012. Devolution of Healthcare Services in Kenya

KPMG International. 2013. Devolution of healthcare services in Kenya: Lessons learnt from other countries. Retrieved 10-July, 2017, from

http://www.kpmg.com/Africa/en/IssuesAndInsights/ArticlesPublications/Documents/Devolution\%20of\%20HC\%20Services\%20in\%20Kenya.pdf

Kristiansen, S. and Santoso, P., 2006. Surviving decentralisation? Impacts of regional autonomy on health service provision in Indonesia. Health Policy, 77(3), pp.247-259.

Kubai, M.M., 2015. Factors Influencing Effective Implementation of Devolution: A Case of Meru County, Kenya. Unpublished Master's Thesis, University of Nairobi, Institute of Development Studies

Lakshminrayanan, R., 2003. Decentralization and its implications for reproductive health: The Philippines experience. Reproductive Health Matters 11(21).

Litvack, J.I., Ahmad, J. and Bird, R.M., 1998. Rethinking decentralization in developing countries. World Bank Publications.

Lynch, G. 2011. I Say to You: Ethnic Politics and the Kalenjin in Kenya. Chicago, IL: University of Chicago Press

Magnussen, J., Hagen, T.P. and Kaarboe, O.M., 2007. Centralized or decentralized? A case study of Norwegian hospital reform. Social science \& medicine, 64(10), pp.21292137.

Matthews, B. and Ross, L., 2014. Research methods. Pearson Higher Ed.

Mawhood, P. (ed.) 1983. Local Government in the Third World: The Experience of Tropical Africa, Wiley, Chichester.

May, T., 2011. Social research. McGraw-Hill Education (UK).

Mechanic, D., 1972. Public expectations and health care.

Mehrotra, S., 2006. Governance and Basic Social Services: Ensuring Accountability in Service Delivery through Deep Democratic Decentralization, Journal of International Development 18: 263-83 
Mills, A., Vaughan, J.P., Smith, D.L., Tabibzadeh, I. and World Health Organization, 1990. Health system decentralization: concepts, issues and country experience. World Health Organization, Geneva.

Mills, A. 1994. Decentralization and Accountability in the Health Sector from an International Perspective; what are the Choices? Public Administration and Development, 14, 3, $281-92$.

Mitchell, A., \& Bossert, J. T., 2010. Decentralization, governance and health-system performance: 'Where You Stand Depends on Where You Sit'. Development Policy Review 28. (6).

MoH. 1999. National Health Sector Strategic Plan: 1999-2004 (NHSSP). Nairobi: Ministry of Health, Health Sector Reform Secretariat.

MoH. 2000. Report of a Workshop on Decentralization. Nairobi: Health Sector Reform Secretariat, Ministry of Health.

MoH. 2005. National health sector strategic plan 2, 2005-2010

MoH. 2007. The Kenya Essential Package for Health, Ministry of Health.

MoH. 2013a. Kenya Health Sector Strategic Plan III, 2013-2018. Nairobi: Government of Kenya.

MoH. 2013b. Kenya Service Availability and Readiness Assessment Mapping (SARAM) Report. Nairobi: World Health Organization

MoH. 2014. Kenya Health Policy 2014-2030 (draft). Nairobi: Government of Kenya.

MoH. 2014. 2013 Kenya Household Health Expenditure and Utilisation Survey. Nairobi: Government of Kenya.

MoH 2015. 2014/2015 National and County Health Budget Analysis Report. Nairobi: Republic of Kenya

MoH. 2016a. National and County Health Budget Analysis FY 2015/16. Nairobi: Republic of Kenya.

MoH 2016b. Kenya's HIV County Profiles 2016. National AIDS and STI Control Programme. National Aids Control Council.

Momanyi, G. O., 2016. Scaling up Motivation for Improved Health System Performance in Narok County, Kenya. Unpublished Master's Thesis, Kenya Methodist University, Department of Health Systems Management

Mosca I., 2005. Is decentralisation the real solution? A three-country study. Health Policy 2006; 77 (June (1)):113 20.

Murkomen, O.K., 2012, October. Devolution and the Health System in Kenya. In Devolution and Health Consultative Meeting. 
Murugu, P.M., 2014. The Challenges and Opportunities of Decentralized Political Systems. Unpublished Master's Thesis, University of Nairobi, Institute of Development Studies

Mutiso, J. and Kagiri, A., 2016. Influence of Devolved Governance on Performance of Health Sector in Kenya: A Case of Machakos County. International Journal of Recent Research in Social Sciences and Humanities (IJRRSSH), 3(4), pp.61-75.

Mutizwa-Mangiza, N.D., 2000. Decentralization for Good Governance and Development: Comment. Regional Development Dialogue, 21, pp.23-5.

Mutua, M. 2008. Kenya's Quest for Democracy: taming Leviathan. Kampala: Fountain Publishers.

Mwabu G., 1995. Health care reform in Kenya: a review of the process. Health Policy pp. 32(1-3):245-55.

Mwamuye, M.K. and Nyamu, H.M., 2014. Devolution of health care system in Kenya: a strategic approach and its implementation in Mombasa County. Kenya Int J Advanced Res, 2(4), pp.263-8.

NCAPD, MOMS, MOPHS, KNBS, ICF Macro. 2011. Kenya Service Provision Assessment Survey 2010. Nairobi, Kenya.

Ndavi, P.M., Ogola, S., Kizito, P.M. and Johnson, K., 2009. Decentralizing Kenya's Health Management System: An Evaluation. University of Nairobi.

Ndegwa, S.N. 2002. Decentralization in Africa: a stocktaking survey. Washington, DC: The World Bank

Ndii, D. 2010. Decentralization in Kenya. World Bank. Available at http://siteresources.worldbank.org/INTAFRICA/Resources/2579941335471959878/ Decentralization_in_Kenya_Background_Note.pdf.

Neuman W.L., 1994. Social Research Methods. Qualitative and Quantitative Approaches, 2nd edn. Allyn and Bacon, Massachusetts.

Ntuala, S., 2010. Factors influencing implementation of Constituency Development Funded Projects: a case of Tigania East Constituency (Unpublished Thesis, University of Nairobi, Kenya).

Nyamori, R.O., 2009. Making Development Accountable: A Critical Analysis of the Systems of Accounting and Accountability for the Constituency Development Fund in Kenya, Journal of Accounting and Organizational Change, Vol. 5 (2); 197-227

Nyanjom, O., 2011. Devolution in Kenya's New Constitution: Constitution Working Paper No. 4. Society for International Development (SID).

Nyikuri, M., Tsofa, B., Barasa, E., Okoth, P. and Molyneux, S., 2015. Crises and resilience at the frontline - public health facility managers under devolution in a Sub-County on the Kenyan Coast. PloS one, 10(12), p.e0144768. 
Nyongesa, H., Munguti, C., Odok, C. and Mokua, W., 2015. Perceptions of medical students towards healthcare devolution: an online cross-sectional study. The Pan African medical journal, 20.

Okech, T. C., \& Lelegwe, S. L., 2016. Analysis of Universal Health Coverage and Equity on Health Care in Kenya. Global Journal of Health Science, 8(7), 218-227. http://doi.org/10.5539/gjhs.v8n7p218

Oyaya CO, Rifikin SB. 2003. Health sector reforms in Kenya: an examination of district level planning. Health Policy 64: 113-127.

Oyugi, W.O. 2000. Decentralization for Good Governance and Development: The Unending Debate. Regional Development Dialogue 21.1: iii-xix

Peckham, S., Exworthy, M., Powell, M., \& Greener, I. 2005. Decentralisation, centralisation and devolution in publicly funded health services: Decentralisation as an organisational model for health care in England. National Co-ordinating Centre for NHS Service Delivery and Organisation R \& D (NCCSDO).

Peckham, S., Exworthy, M., Powell, M., \& Greener, I. 2008. Decentralizing health services in the UK: a new conceptual framework. Public Administration, 86(2), 559-580.

Penchansky, R. and Thomas, J.W., 1981. The concept of access: definition and relationship to consumer satisfaction. Medical care, pp.127-140.

Pollitt, C., J. Brichall and K. Putnam. 1998. Decentralising Public Service Management. London: Macmillan.

Prud'homme, R. 1995. The dangers of decentralization. The World Bank Research Observer 10(2), 201-220.

Regmi, K., Naidoo, J., Greer, A. and Pilkington, P., 2010. Understanding the effect of decentralisation on health services: the Nepalese experience. Journal of health organization and management, 24(4), pp.361-382.

Robinson, M. 2003. Participation, local governance and decentralized service delivery. Workshop on new approaches to decentralized service delivery.

Robinson, M., 2007. Does decentralisation improve equity and efficiency in public service delivery provision? IDS bulletin, 38(1), pp.7-17.

Rondinelli, D. A. 1981. 'Government decentralization in comparative perspective: theory and practice in developing countries', International Review of Administrative Sciences, 47, 136- 145.

Rondinelli, D. A. 1983. Decentralization of development administration in East Africa. In Decentralisation and Development, edited by G. S. Cheema and D. A. Kondinelli, pp. 77-126. Sage, Beverly Ilills, Calif.

Rondinelli, D. and Cheema, G. S. 1983. Implementing decentralization policies: an introduction. In Decentralization and Development: Policy Implementation in 
Developing Countries, ed. G. S.Cheema and D. Rondinelli, pp. 9-34. Sage, Beverly Hills.

Rondinelli Dennis, A., Nellis John, R. and Cheema, G.S., 1983. Decentralization in Developing Countries. A Review of Recent Experience. World Bank Staff Working Papers, (581).

Rondinelli, D.A., McCullough, J.S. and Johnson, R.W., 1989. Analysing decentralization policies in developing countries: a political-economy framework. Development and change, 20(1), pp.57-87.

Sharma, Y., \& Mwonge, A. 2010. An opportunity to improve service delivery in Nepal through local governance. Nepal Study Center, University of Mexico.

Shrestha, J., 2010. Evaluation of Access to Primary Healthcare: A Case Study of Yogyakarta, Indonesia. University of Twente Faculty of Geo-Information and Earth Observation (ITC).

Simatupang, R. R. 2009. Evaluation of decentralization outcomes in Indonesia: Analysis of health and education sectors. Economics Dissertations Paper 58. Department of Economics, Georgia State University. Available from http://http://digitalarchive.gsu.edu/cgi/viewcontent.cgi?article=1062\&context=econ diss

Sjahrir, S. B., \& Kiskatos, K. 2011. Does local governments' responsiveness increase with decentralization and democratization? Evidence from sub-national budget allocation in Indonesia. University of Freiburg, Department of International Economic Policy.

Smith, B.C. 1985. Decentralisation: The Territorial Dimension of the State, London: George Allen and Unwin.

Social Protection Committee, 2013. Thematic In-Depth Reviews on the 2013 SPPM 'Social Trends to Watch': Organization. SPC/2014/03/1, Brussels, 13 March.

To, A., 2003. Health for all beyond 2000: the demise of the Alma-Ata Declaration and primary health care in developing countries. The Medical Journal of Australia, 178(1), pp.17-20.

Tsofa, B., Molyneux, S. and Goodman, C., 2016. Health sector operational planning and budgeting processes in Kenya- "never the twain shall meet". The International journal of health planning and management, 31(3), pp.260-276.

U.N. 1962. Decentralization for National and Local Development, U.N., New York.

United Nations Development Program, Rural Development: Issues and Approaches for Technical Cooperation, Evaluation Study No. 2 (New York UNDP, 1979), p. 104

USAID. 2014. Case Study: Kenya National Hospital Insurance Fund (NHIF) Premium Collection for the Informal Sector

Wamai, R.G. 2009. Healthcare policy administration and reforms in post-colonial Kenya and challenges for the future. Local and Global Encounters: Norms, Identities and 
Representations in Formation. The Renvall Institute for Area and Cultural Studies: Helsinki.

Wang, H., Wolock, T.M., Carter, A., Nguyen, G., Kyu, H.H., Gakidou, E., Hay, S.I., Mills, E.J., Trickey, A., Msemburi, W. and Coates, M.M., 2016. Estimates of global, regional, and national incidence, prevalence, and mortality of HIV, 1980-2015: the Global Burden of Disease Study 2015. The lancet. HIV, 3(8), pp.e361-87.

WHO 2008. Closing the gap in a generation: health equity through action on the social determinants of health: Commission on Social Determinants of Health final report. World Health Organization.

World Bank.1987. Financing Health Services in Developing Countries: An Agenda for Reform. Washington, D.C.

World Bank. 1993. World Development Report 1993: Investing In Health. World Bank, Washington, DC.

World Bank. 1994. World Development Report 1994, Washington DC: World Bank.

World Bank. 2002. Decentralization and Health in the Philippines and Indonesia: An Interim Report. Washington DC: World Bank.

World Bank 2005. Decentralisation and Subnational Regional Economics website.

World Bank and CMI. 2012. Service Delivery Indicators: Project Concept. Available at http://www.sdindicators.org/wp-content/uploads/2013/06/Service-DeliveryIndicators-Program-Concept.pdf

World Bank. 2012. World Bank Fiscal Decentralisation Knowledge Programme Team. Devolution without Disruption: Pathways to a Successful New Kenya.

World Bank. n.d. Health Expenditure, Total (percent of GDP). Retrieved from http://data.worldbank.org/indicator/SH.XPD.TOTL.ZS

World Bank Group. n.d. "What, Why, Where." Decentralization \& Subnational Regional Economics. Available at http://www1.worldbank.org/publicsector/decentralization/what.html.

World Development Report 1993: Investing in Health. Washington, DC: The World Bank. WHO, 1978. Alma Ata Declaration. Geneva: World Health Organization.

WHO. 2006. Quality of Care: A Process for Making Strategic Choices in Health Systems. Geneva: WHO.

Yee E. 2001. The Effects of Fiscal Decentralisation on Health Care in China. University Avenue Undergraduate Journal of Economics, Princeton University.

Yin, R.K., 2009. Case study research: Design and Methods. (4 ${ }^{\text {th }}$ ed). Thousand oaks, CA: Sage. Yin, R.K., 2012. Applications of case study research. Sage 